\title{
Research and Training in Culturo-Behavior Science
}

\author{
Traci M. Cihon ${ }^{1}$ (D) $\cdot$ Aécio Borba ${ }^{2} \cdot$ Marcelo Benvenuti $^{3} \cdot$ Ingunn Sandaker $^{4}$
}

Accepted: 23 September 2021 / Published online: 1 December 2021

(C) Association for Behavior Analysis International 2021

\begin{abstract}
Culturo-behavior science (CBS) is a developing area and recently formalized specialization in behavior science that brings together principles and techniques from behavior analysis (e.g., Skinner, 1953), behavioral systems analysis (e.g., Brethower, 2008), cultural analysis (e.g., Glenn et al., 2016), and cultural systems analysis (Mattaini, 2020). Culturo-behavior scientists typically work within a selectionist and/ or (ecological) systems perspective to advance our understanding of how cultural phenomena develop and change over time and how more effective cultures and systems can be designed (Cihon \& Mattaini, 2019, 2020b). The purpose of the current article is to describe CBS, to introduce the recently formulated Association for Behavior Analysis International verified course sequence (VCS) and certificate program in CBS, and to present different pathways to training in CBS. We do this through the presentation of examples from the literature and from four universities that have adopted the CBS VCS and certificate program that are illustrative of how different programs may approach research and training in CBS.
\end{abstract}

Keywords behavioral systems analysis · cultural analysis · cultural systems analysis . culturo-behavior science $\cdot$ education and training of behavior scientists

Portions of this article were presented at the Culturo-Behavior Science for a Better World conference in 2020 and at the 2021 conference of the American Psychological Association, Division 25. We would also like to thank the members of our respective labs and the community partners who assisted in and contributed to many of the projects described throughout, as well as the members of the Association for Behavior Analysis International task force who developed the competencies for the culturo-behavior science course sequence and certificate program.

Traci M. Cihon

traci.cihon@unt.edu

1 Department of Behavior Analysis, University of North Texas, 1155 Union Circle \#310919, Denton, TX 76203, USA

2 Universidade Federal do Pará, Belém, Brazil

3 University of São Paulo, São Paulo, Brazil

4 Oslo Metropolitan University, Oslo, Norway 


\section{Research and Training in Culturo-Behavior Science}

Several behavior scientists have long considered and worked toward developing a natural science of behavior that would allow for the identification of basic concepts and principles applicable to building a better world (e.g., Chance, 2007; Cihon \& Mattaini, 2020b; Dixon et al., 2018; Leigland, 2011; Mattaini, 2019; Rumph et al., 2005). Skinner (1948a), for example, imagined Walden Two, the design of which was grounded in an understanding of a natural science of behavior and the basic principles of behavior change. The application of behavioral principles was further combined with participatory practices (e.g., F. Baum et al., 2006) that engaged community members in continual experimental analysis and a behavioral systems analysis of the community itself. This complex (yet simple; Malott, 2003) approach to community design provided the foundation by which the Walden Two board of planners could ensure the establishment and continual revision of the networks of contingencies arranged to promote, evoke, and sustain patterns of cultural practices (e.g., macrobehaviors, interlocking behavioral contingencies [IBCs], and culturants; Glenn et al., 2016) that were both desirable to the community members and integral to the community's survival. Skinner's (1948a) Walden Two, despite its fictional and utopian underpinnings, may be one of the earliest examples in the behavioral literature of how scientific literacy can support social activism.

The work of behavior scientists in developing a natural science of behavior and a conceptually systematic technology with applications for social change is in some ways reminiscent of Francis Bacon's (n.d.) proverb-knowledge is power. The manifestation of knowledge as the power of social change is highlighted in how the characterization of how modern society changed from industrial societies to informational societies (e.g., Crawford, 1983; Fritz, 1962) and more recently to knowledge societies (e.g., Castelfranchi, 2007; Innerarity, 2012). These changes show how knowledge has become increasingly important for characterizing modern societies and for describing the close relationship among wealth production, prosperity, power, and knowledge. The implications are highlighted in the recognition of the importance of equity in the distribution of knowledge in society by the United Nations Educational, Scientific and Cultural Organization (UNESCO, 2005). Further defining knowledge as an understanding of the experimental processes and basic principles governing natural phenomena is collectively perhaps what is meant by scientific literacy. Knowledge may be transformed into power when the intertwined and dynamic demand for networks of transdisciplinary, collaborative relationships focused on change is further combined with participatory approaches and nonviolent strategic action (Ardila-Sánchez et al., 2020; Mattaini, 2013). Thus, the adage knowledge is power refers to the confluence of conditions and contingencies necessary for social change.

However, for many social activists and applied researchers, once a technology that can solve a social problem is found, basic science can lose some of its importance. Dealing with the grand challenges facing humanity - the wicked (Rittel \& Webber, 1973) and superwicked (Levin et al., 2012) problems - can become more important than investing in abstract understandings of basic principles or even in the prediction of natural phenomena. In fact, ideas such as social, economic, and environmental justice; human rights; environmental change and sustainability; and more require urgent solutions (e.g., Ledoux, 2014, 2017; Mattaini, 2019). For this reason, knowledge 
directly related to behavior change on a large scale is usually viewed as more important for social change than the knowledge directly related to advancing the basic science. The first is assumed to deal with "real-world problems," whereas the second is viewed as something unrelated and distant from social demands in a world that claims to value social change. Nonetheless, the knowledge that comes from basic science is probably the most fundamental source of power in modern societies and is perhaps even more influential as an initial step toward technological advances and innovation. Basic science and principles help define areas of investigation and intervention and support multi-, inter-, and transdisciplinary approaches toward these aims (culturo-behavior science [CBS] is inherently inter- or transdisciplinary as its subject matter often overlaps or intersects with anthropology, economics, biology, sociology, and many other disciplines). The job of behavior scientists, and culturo-behavior scientists, is to show how behavior principles, culturo-behavior principles, social behavior, and cultural practices are important areas of research and are new and important frontiers to explore.

Technology and innovation are only one aspect of scientific development. We submit that basic science in CBS is also a "real-world problem" in the sense that it explores fundamental questions of human existence, constantly reviews comprehension of the basic phenomena, provides a deep understanding of why certain practices work (or do not work) or sustain (or do not sustain), and, importantly, connects us with other sciences. Basic science is what makes scientific literacy a key component of social activism: We cannot simply be efficient in promoting behavior and social change on a large scale; we must also inform people about what behavior means, what cultural practices are, and what contingencies evoke and sustain them. By taking these steps, we support people in independently making better decisions in their daily lives. Research and training in CBS, and the mission of CBS more generally, highlight the importance of the mutual relationships among basic science, applied science, programs for largescale behavior change, and scientific literacy.

The purpose of the current article is to further describe CBS; to introduce the recently formulated Association for Behavior Analysis International (ABAI) verified course sequence (VCS) and certificate program in CBS, including the experientiallearning component; and to present different pathways to training in CBS. We do this through the presentation of examples from the literature and from four universities that have adopted the CBS VCS and certificate program that are illustrative of how different programs may approach research and training in CBS.

\section{CBS: An Emerging Area in Behavior Science}

CBS is a developing area and recently formalized specialization in behavior science that brings together principles and techniques from behavior analysis (e.g., Skinner, 1953), behavioral systems analysis (BSA; e.g., Brethower, 2008), cultural analysis (e.g., Glenn et al., 2016), and cultural systems analysis (Mattaini, 2020). Culturobehavior scientists typically work within a selectionist and/or (ecological) systems perspective to advance our understanding of how cultural phenomena develop and change over time and how more effective cultures and systems can be designed (Cihon 
\& Mattaini, 2019, 2020b). CBS is inherently interdisciplinary if not transdisciplinary, with

scholars and practitioners working in applications of behavior science to cultural and community change com[ing] from numerous traditions within behavior science including behavioral community psychology, organizational behavior management (e.g., Diener et al., 2009), behavioral systems analysis (e.g., Houmanfar et al., 2010; Malott, 2003), and cultural analysis (e.g., Glenn, 2004), [who] have been influenced by a number of complementary disciplines including social work, psychology, education, biology, systems science, anthropology, and more. (Cihon \& Mattaini, 2020b, p. 2)

CBS bridges concepts and principles from behavior analysis with those from other disciplines. It also requires connections and collaborations within our own discipline (see Fig. 1) with researchers and practitioners who are "united by the philosophy of radical behaviorism and by their commitment to apply the natural science of behavior to understanding behavior in its social and cultural environments" (Cihon \& Mattaini, 2020b, p. 2).

Given the number, severity, and urgency of the challenges facing humanity (Ledoux, 2014, 2017; Mattaini, 2019), now and in the future, CBS, as a specialty in behavior analysis, gives us the best chance of understanding and contributing to redefining the systems and structural contingencies that contribute to significant social issues (Cihon \& Mattaini, 2020a, 2020b). It emphasizes the recursive relations between human behavior and the networks of contingencies that make up our social and cultural environments. Research in public health (U.S. Department of Health and Human Services, n.d.), for example, clearly indicates the correlation between certain societal, cultural, and environmental conditions (i.e., social determinants of health) and health outcomes (i.e., morbidity and mortality). There are numerous examples of communitybased interventions, strategic plans, and theoretical frameworks that support

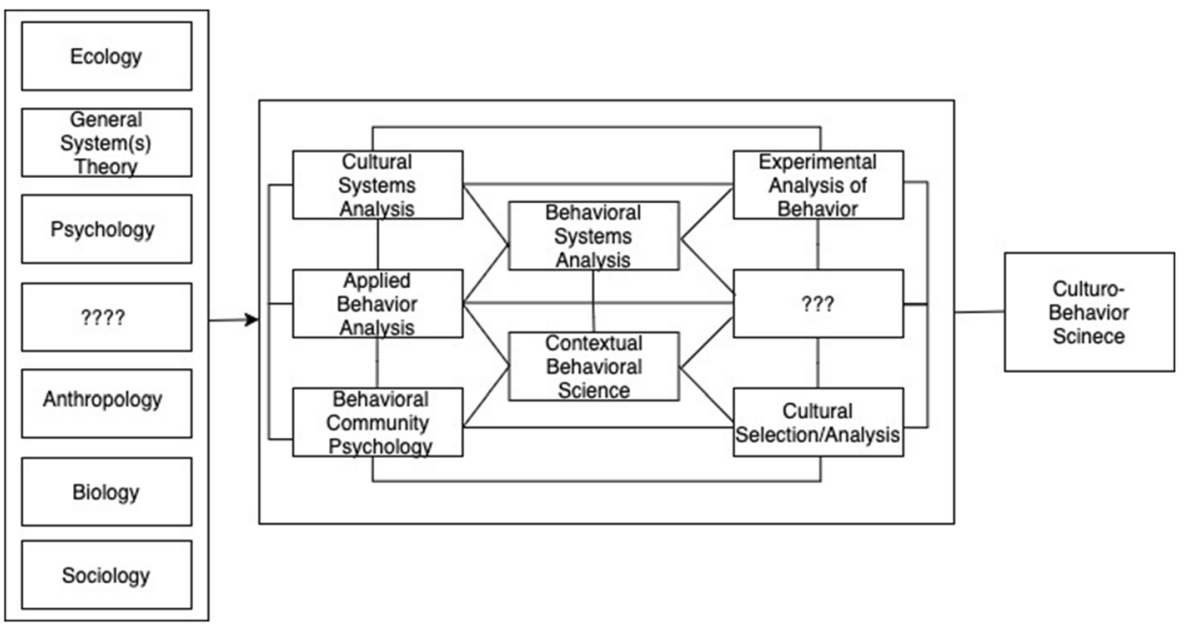

Fig. 1 A sample of some of the discipline areas outside of behavior analysis and some of the specializations within behavior science that work together to form a culturo-behavior science 
communities and community members in overcoming these barriers to improved health (see e.g., Biglan et al., 2020; Community Toolbox, 2021; Substance Abuse and Mental Health Services Administration, 2019; Watson-Thompson, Francisco, et al., 2020; Watson-Thompson, Jessop, et al., 2020). Yet despite the clear role of human behavior in constructing these systemic contingencies, the strategies and tactics to affect the behaviors and practices that lead to the inequities across communities are less clear (e.g., work in policy development and adoption; Mattaini et al., 2020). Work in CBS that also emphasizes cooperative and coordinated responding (e.g., Ardila-Sánchez et al., 2020; Cihon, Borba, et al., 2020; Schmitt, 1998) and systems' interdependencies (cf. Mattaini, 2013, 2019) can contribute to these efforts. Such work, often grounded in strategies for community mobilization (cf. Khasnabis et al., 2010), the formation of community coalitions (Community Toolbox, 2021), and more, underscores the importance of furthering our understanding of the basic mechanisms critical to cooperative and coordinated efforts. The work often consists of efforts to identify the contingencies supporting social behavior and how one person's behavior may serve as the antecedents or consequences for another's behavior (e.g., Glenn et al., 2016; Skinner, 1953), to identify the contingencies selecting these responses as units of analysis in and of themselves (i.e., culturants; Hunter, 2012), and to identify the dynamics that facilitate systems' interdependencies and interactions (e.g., culturobehavioral hypercycles; Krispin, 2017, 2019; and systems interdependencies; Mattaini, 2013).

Not all behavior scientists agree on what constitutes the paths forward for CBS (see, e.g., Branch, 2006; Marr, 2006; Mattaini, 2006; Zilio, 2019). Yet variability is important for advancing the science (Skinner, 1981), and few would argue that behavior science does not have an important role to play in understanding the contingencies that evoke and sustain human behaviors that contribute to larger social issues. We are not doing so well as a species - from a global pandemic and economic crisis (Brownson et al., 2020) to climate change (Alavosius \& Houmanfar, 2020; Gelino et al., 2020; Grant \& Forrest, 2020), racism (e.g., Mattaini \& Rehfeldt, 2020), and violence (Roose \& Mattaini, 2020), these social issues are all rooted in human behavior and the contingencies that support it. CBS may provide us with the best opportunity to not only understand these grand challenges but also construct more socially and environmentally just communities and systems (Cihon \& Kazaoka, 2021; Cihon \& Mattaini, 2019, 2020b).

Recently, scholars, practitioners, aspiring behavior scientists and behavior analysts, and others (e.g., Cihon, Becker, et al., 2020; Mattaini, 2019; Mattaini \& Luke, 2014) have commented on the numerous barriers to accessing training in CBS and other applications of behavior science to design more effective behavioral systems. Nevertheless, the students are ready; they see the problems and they see that the problems are largely caused by human behavior. They want to better understand the recursive relations between human behavior and the networks of contingencies that make up our social and cultural environments, the sector interdependencies, and nonviolent strategic social action (Ardila-Sánchez et al., 2020; Cihon, Becker, et al., 2020; Mattaini, 2013). There is an explicit need for training in CBS, and recent efforts from ABAI, the Behaviorists for Social Responsibility Special Interest Group (BFSR SIG) of ABAI, and members of the think tanks on cultural analysis (Glenn et al., 2016; Mattaini \& Cihon, 2019; Todorov \& Malott, 2005) have begun to shape an 
infrastructure to support and expand opportunities for students to receive explicit training in CBS.

\section{VCS and Certificate Program}

The barriers and motivations for expanding training opportunities for behavior scientists interested in CBS were recently recognized by ABAI. In the fall of 2019, ABAI formed a task force that sought to address these challenges. The members coined the phrase culturo-behavior science in an effort "to capture the breadth of work focused on cultural and behavioral systems science" (Cihon \& Mattaini, 2019, p. 700) and moved forward with the development of a VCS and certificate program in CBS (ABAI, n.d.). ${ }^{1}$ The new VCS and certificate program in CBS requires that students develop competencies in foundational knowledge in behavior science and in cultural and behavioral systems science. Additionally, CBS VCSs must include an experientiallearning component that provides students with the opportunity to develop competencies in CBS research and practice. The experiential-learning component requires interdisciplinary collaboration, often cultivated through advising and mentoring students in faculty-advised research and teaching labs through practica, special-problems courses, theses, and dissertations (Cihon, Becker, et al., 2020). The emphasis is on establishing a critical recombinative repertoire (cf. Alessi, 1987; Cihon, Becker, et al., 2020) so that students, upon completion of the certificate program, are prepared to practice, explore, and advance CBS.

Currently, only six universities worldwide offer the CBS VCS and certificate. There are three such programs in Brazil, one in Norway, and two in the United States. Each of these programs offers coursework grounded in concepts and principles that constitute foundational knowledge in behavior science more generally, a course in BSA, and courses tied to experiential learning in which students receive interdisciplinary supervision in the application of behavior science and CBS to advancing basic research, exploring applications thereof, and translating such work into practice.

\section{Foundational Knowledge and Competencies}

As discussed earlier and elsewhere (e.g., Cihon \& Mattaini, 2019), CBS is influenced by various sciences and practices, generating a wide range of publications in the conceptual (e.g., Glenn, 2004), interpretative (e.g., Borba, 2019), experimental (e.g., Vichi et al., 2009), and applied work (e.g., Watson-Thompson, Francisco, et al., 2020; Watson-Thompson, Jessop, et al., 2020). Despite this variety, three of the main aspects that ground and unify this work are a solid foundation in behavior-analytic concepts, a behavior-analytic worldview, and a data-driven spirit that supports the evaluation and reformulation of concepts and practices.

Behavior scientists have a very particular way of understanding human behavior. Instead of explaining behavior based on hypothetical constructs or genetic variables, behavior scientists look at contingencies of reinforcement found in the environment to understand which variables affect behavior and how they affect behavior (Skinner, 1953, 1974). Looking at environmental contingencies is one of the critical features of a

\footnotetext{
${ }^{1}$ It is important to highlight that the CBS program is a certificate program and not a certification program.
} 
natural science of behavior that allows behavior scientists to be effective in changing these contingencies, thus promoting behavior change.

When moving to understand cultural and societal problems, CBS researchers and practitioners cannot leave the basic science behind. As such, understanding foundational knowledge in behavior science and the corresponding concepts and principles is the first step in developing the repertoire required for students interested in CBS. The objective of the courses that provide the foundational knowledge in behavior science is to arrange contingencies such that upon completion, the student can identify the main concepts of behavior analysis, analyze behavior using such concepts, and discuss the implications of these concepts for experimental and applied research and practice. Examples of the items included in this area are identifying the three kinds of selection as described by Skinner (1981) and how they relate to one another, describing and differentiating operant and respondent behavior, and more. When approaching cultural phenomena, behavior scientists will also have to look to some of the more "advanced" concepts in the field: Examples include choice and molar aspects of behavior-environment interactions (e.g., W. M. Baum, 2018; Herrnstein, 1970), equivalence relations and relational responding (e.g., Fryling et al., 2020; Sidman, 1994), and verbal behavior (e.g., Skinner, 1957), to name only a few. Many CBS concepts are built upon both these and other basic concepts. For example, it may be difficult for students to understand IBCs (e.g., Glenn, 2004) if they are not able to describe contingencies of reinforcement and social behavior (e.g., Azrin \& Lindsley, 1956).

The Appendix A1 presents course objectives, items, and competencies the ABAI task force adopted for the foundational knowledge courses. This component may be easier to offer in behavior analysis programs and in classes such as Introduction to Behavior Analysis, Fundamentals of Behavior Analysis, and so on, as it roughly corresponds to what is required for the philosophical underpinnings of the science for ABAI accredited programs and VCSs that prepare students for certification (e.g., concepts and principles; ABAI, n.d.; Behavior Analyst Certification Board, n.d.). In such courses that are also a part of the CBS VCS, the instructor may focus on or add to the discussion how those concepts apply to social behavior. Even if the foundational knowledge component of the CBS VCS and certificate program may be easier to integrate into behavior analysis programs, it is important that we invite those from other disciplines to take part in these courses, and offer such courses to those in other disciplines such as social work, public health, and psychology. These disciplines, and others, could benefit from merging a CBS framework into their research and practice, and culturo-behavior scientists have much to learn from these disciplines.

The reader may also notice that included in many of the competencies are reading, analyzing, and understanding basic research. This is grounded in the idea that consuming and understanding basic research are essential skills for behavior scientists - even those who are focused primarily on its applications. The link between basic principles and the application to problems of social importance has been pointed out by others in the discussion of behavior science more generally (e.g., Mace \& Critchfield, 2010; Sidman, 2011) and should not be lost on those interested in tackling social problems. Basic research on the concepts and principles of CBS is just one of the ways in which behavior scientists can support students interested in mitigating social issues to develop the desired repertoire that will enhance their later applications and practice. 
One example of such work, from the Laboratory of Experimental Analysis of Social Behavior and Cultural Practices at the University of São Paulo (LEASBC-USP), uses a task called the free culturant (de Toledo et al., 2015), which permits CBS researchers to use schedules of reinforcement as baselines and to create the demand for group coordination. In this sense, the free-culturant task makes it possible to see the simultaneous occurrence of two units of analysis - one related to the correlation between individual behavior and reinforcement and one related to the correlation between group organization (temporal coordination) and mutual or cultural outcomes. Two studies (de Toledo, Benvenuti, Sampaio, et al., 2015; de Toledo, Benvenuti, Marques, et al., 2020) have shown that demands for coordination may have a tremendous impact on individual behavior maintained by schedules of reinforcement. Moreover, this impact may be differentially affected if participants were working on interval or ratio schedules.

Another example from LEASBC-USP is related to superstitious behavior. Individual behavior may be affected by contiguity and can generate superstitious behavior (Skinner, 1948b). Skinner (1948b) generated superstitious behavior with a procedure that involved the noncontingent presentation of food to pigeons, creating a situation in which their behavior was subjected to the pitfalls of contiguity. Later, Higgins et al. (1989) investigated superstitious behavior in a more complex situation, in which children served as the participants in an experiment in which noncontingent presentations of marbles was alternated with another condition in which no marbles were presented (i.e., multiple schedules of reinforcement). This experimental arrangement allowed Higgins et al. to investigate the interaction between superstitious behavior and social variables, such as instructions and modeling. The conditions and contingencies provided information about how social variables may affect superstition, in the sense that the social variables may participate in the social transmission of superstition in children.

Subsequently, Benvenuti et al. (2018) evaluated the social transmission of superstitious behavior in an experiment involving participant replacement (inspired by Caldwell \& Millen's, 2008a, 2008b, 2009, procedure to study cumulative cultural evolution). The experiment begins with the first participant observing a confederate who behaves "superstitiously," engaging in a high rate of responses when points are presented independent of behavior and not responding when points are not presented. After $5 \mathrm{~min}$, the observer takes the place of the confederate, and participants are continually replaced throughout the experiment. The results show a lot of variability in responding with individual exposure in noncontingent situations. However, in the conditions with participant replacement, there is no variability. In fact, there is an unexpected uniformity in the data. These data permit us to ask questions about the role of coincidence in behaviors transmitted across generations by means of cultural mechanisms. Social mechanisms related to superstitious behavior may, for instance, be an important variable to consider when such mechanisms are used to instruct others as to how to behave in situations in which behavior can be affected by coincidence. Like the previous example relating schedules of reinforcement to coordinated responding, the social aspect of superstitious behavior may serve to integrate some of the core aspects of CBS with basic principles of behavior analysis. 


\section{BSA and Competencies}

In the second course, students are introduced to key concepts from BSA, systems science, and cultural analysis. The course consists of 12 units that support the students' development of two of the three general learning outcomes (see Appendix A2 and ABAI, n.d.): First, they must explain the conceptual development and technological applications of BSA, and, second, they must describe the conceptual, methodological, and technological strengths and weaknesses associated with this approach. Several additional course units, designed as rotating special topics, focus on specific applications of CBS (e.g., activism, advocacy, and accompaniment; sustainability; community-based interventions; organizational behavior management; etc.). These units can be adjusted based on students' interests, instructors' experience, and/or societal need and support the students' development of the third general learning outcome for the course (see Appendix B A2 and ABAI, n.d.): integrating themes and topics in behavior analysis that may contribute to the conceptual, methodological, and technological development of BSA.

BSA and CBS support the development of behavioral solutions to socially significant problems within large social units like organizations, cultures, and communities (Cihon \& Mattaini, 2020a). Conceptual analyses, however, have advanced ahead of empirical work, and the field has many opportunities for research and development (Cihon, Borba, et al., 2020). The course in BSA and CBS may be organized around discussions that explore BSA models for stewardship in organizations and sustainability of cultural practices in organizations, communities, and cultures. Such exploration creates opportunities for innovation, discussion, and application of social-cultural units to growing social upheaval, technological advances, and environmental concerns, as well as crises in the global economy, health, education, and more. Empirical and conceptual developments increasingly suggest that behavior is best understood as part of an ecosystem of behavior-environment relations in which perturbations in one set of variables impact other sets of variables and their interaction with the behavior of an organism (Mattaini, 2019, 2020; Morris \& Midgley, 1990). Thus, the course emphasizes teaching students to identify such systemic interactions and to learn how to create and influence systemic interactions.

Some students who are interested in BSA and CBS and who are pursuing the CBS VCS certificate at the University of North Texas (UNT) gain additional experience in one of three faculty-based research labs. The Evolutionary Culture Lab, coordinated by Dr. April Becker, "explores culturo-behavioral phenomena, biological and social systems, and social learning with an emphasis on animal culture, emergent and dynamical systems concepts, multi-level selection, and radical behaviorism" (UNT College of Health and Public Service, n.d., Section 5). The CBS lab, coordinated by Dr. Traci Cihon, explores conceptual and philosophical considerations of the science and conducts basic, translational, and applied research on topics such as arranging contingencies to promote cooperation in various contexts (e.g., to reduce inequitable access to resources), analyzing various organizational and community systems (e.g., academic departments, community gardens) to identify practices that maximize organizational performance and efficiency, and exploring the contingencies that support nonviolent strategic social action. The Community Lab, cofacilitated by Drs. Shahla Ala'i, Malika Pritchett, Alicia Re Cruz, and Traci Cihon, serves as a setting for 
students to engage in collaborative community building through developing and implementing third-way approaches (i.e., those solutions that move beyond an eitheror dichotomy) to address expressed community needs in the most loving and progressive ways possible. The focus of the research and practice conducted within and across these three labs spans from philosophical, theoretical, and conceptual considerations to basic, translational, and applied research (cf. Neef \& Peterson, 2003).

To zoom in a bit on the research lines in the CBS lab, they are diverse yet connected in an attempt to address some of society's most difficult challenges through the scholarship of teaching and learning (e.g., identifying the most effective and engaging strategies to introduce diverse groups of students to the basic principles of behavior science), behavioral approaches to education (e.g., identifying effective instructional strategies to support the development of students' repertoires as related to being actively engaged leaders in their communities), and CBS (e.g., identifying the basic concepts, principles, and procedures to promote ethically self-controlled behavior even when operant contingencies are in competition with responses that promote higher quality, delayed outcomes for the group). The social problems and challenges on which the research is focused have a direct link to the areas of concern for behavior scientists across multiple disciplinary domains, including but not limited to behavior analysis, education, social work, and public health. Grounded in selectionist and ecological systems perspectives, reaching toward social, economic, and environmental justice through modes of inquiry consistent with participatory-action research methods, the general goals of the lab are to conceptualize and contribute to solutions to the world's most pressing problems - namely, the social, economic, and environmental health of communities. Some of the topics we have explored include defining and measuring cultural cusps, exploring contingencies to support coordinated responding to reduce the inequitable distribution of resources (Lopez et al., in press), conducting behavioral systems analyses to support the sustainability of community gardens (Cran et al., 2021), exploring contingencies to promote nonviolent strategic action (Cihon \& Kazaoka, 2021), and teaching leadership, community engagement, and CBS to local high school students (Cihon et al., 2021). Two examples of the work conducted in the CBS lab are elaborated on here to highlight how the work coincides with the specific competencies developed in part through the course in BSA and how ecological and behavior systems science and operant and cultural selection can both support a clearer understanding of significant social issues and foster the development of applications of CBS to strengthen cultures, communities, and organizations.

The first example highlights the applicability of CBS to support and promote cultural practices related to sustainability efforts (Cran et al., 2021). Current food production methods in the United States contribute to environmental degradation, as well as food insecurity. Food production by means of community gardens has the potential to reduce the deleterious effects of current production methods. However, many community gardens face challenges that hinder their longevity, thereby reducing the likelihood of the support they might provide for environmentally sustainable food production and decreased food insecurity for community members. Motivated in part by Cran et al.'s (2021) interest in sustainable practices and supported by the network Cran established and the skills gained during her internship experience with a community-based organization that was building a coalition and network of support for local community gardens, Cran et al. conducted a culturo-behavioral systems 
science analysis of community gardens in order to gain a comprehensive understanding of the variables and practices that support their longevity. Applying concepts and principles from BSA (i.e., the behavioral systems engineering model [BSEM]; Diener et al., 2009; Malott, 2003) and CBS (i.e., matrix analysis; Biglan, 1995; Mattaini, 2013) in combination with ethnographic research methods (Carvalho et al., 2017; Sangaramoorthy \& Kroeger, 2020) and a literature review, the purpose of Cran et al.'s research was to gain a comprehensive understanding of the variables and practices that support the longevity of community gardens. Based on the results of the analysis, Cran et al. were able to make recommendations to the community garden personnel regarding how they might increase the gardens' longevity, thus highlighting the applicability of CBS to support and promote cultural practices related to sustainability efforts.

The second example illustrates the role of laboratory research conducted within metacontingency arrangements and its applicability to understanding and mitigating significant social issues. Several behavioral scientists have used social dilemma games like the iterated prisoner's dilemma game (IPDG) along with principles from CBS in an attempt to understand the variables that influence cooperation and the conditions under which cooperation is most likely to occur (Morford \& Cihon, 2013; Ortu et al., 2012; see also Cihon, Borba, et al., 2020, for a review). However, research regarding how the metacontingency might affect cooperation in asymmetric IPDGs that construct conditions in an asymmetric or unequal way, perhaps more consistent with the world outside of the laboratory, has not been explored. Such experiments might help behavior scientists to better understand how unequal conditions contribute to or disrupt cooperative behavior. Lopez et al. (in press) explored cooperation using an asymmetric IPDG with a metacontingency manipulation. Cooperation was defined as the oscillation between two target aggregate products (APs) across two consecutive cycles that required the individuals to engage in IBCs that resulted in one AP during one cycle and in IBCs that resulted in a different AP in the following cycle to produce the cultural consequence. The payoff matrix was made to favor one participant for the first half of the experiment and the other participant for the second half. Lopez et al. noted that if it is possible to determine the effects of unequal conditions on cooperation, behavior scientists might be able to determine contingency arrangements at the individual or cultural level that will promote cooperative behavior in conditions in which disparities are prevalent.

The work of Cran et al. (2021) and Lopez et al. (in press) highlights the scope of research and practice related to BSA and CBS. Students in the BSA course develop familiarity with the concepts and tools from BSA and CBS employed by Cran et al. and Lopez et al. Notably, students learn both the BSEM and its application to organizational change, as well as the matrix analysis (Biglan, 1995; Mattaini, 2013; Seniuk et al., 2019), in completing an analysis of a socially important issue in their local community. As an example of the latter, students identify a social issue of importance to them (e.g., teacher retention, the availability of no-kill animal shelters, mass incarceration). They conduct research that supports the identification of key actors and sectors and the behaviors and practices they engage in that contribute to sustaining the problem. Next, students identify the motivating contexts (e.g., motivating operations and discriminative stimuli) that evoke the behaviors and practices or increase the value of the consequence associated with such behaviors and practices, 
the consequences that sustain the behaviors and practices, and the interdependencies among the behaviors and practices and the corresponding contingencies. After completing the matrix analysis of the problem of interest, students complete a second matrix analysis that follows a similar set of steps; however, the focus of the second matrix analysis is on identifying alternative sets of behaviors/practices and the corresponding contingencies to support them, as well as on identifying pathways that interrupt the behaviors and practices sustaining the social issue. Often BSA is considered applicable only to those interested in the applications of behavior science to organizations and business (e.g., Ludwig \& Houmanfar, 2010), and CBS is equated with laboratory experiments on the metacontingency (Cihon, Borba, et al., 2020) and interpretations of complex social issues (e.g., Lamal, 1991, 1997) with few examples of application. However, tools like the matrix analysis (Mattaini \& Luke, 2014) have been applied to mitigating significant health risks (e.g., smoking cessation; Biglan, 1995), understanding the conditions that increase the success of strategic nonviolent resistance (Mattaini, 2013), and increasing behavior scientists' attention to significant social issues like sustainability (Seniuk et al., 2019). Cran et al.'s work highlights how the combination of tools from BSA and CBS can contribute to strengthening one's local community. The work of Lopez et al. emphasizes the opportunity for laboratory scientists to contribute to a clearer understanding of how interventions might be arranged to capture the complexity of social behavior as it occurs within cultural, political, and economic systems and the associated networks of contingencies in current social policy.

\section{Experiential Learning}

The third course in the CBS VCS provides the opportunity for students to engage in supervised research and practice in CBS. Through these experiential-learning courses, students develop competencies related to specific strategies for CBS, including the relation between individual behavior and the networks of contingencies inherent in social and cultural systems; the relation between metacontingencies and general system(s) theory (von Bertalanffy, 1968); function, processes, and structure (Bento et al., 2020); and more (see Appendix A3). As behavior scientists, it should be easy to acknowledge that applying concepts, methods, and technologies in practice involves a different behavioral repertoire from simply describing concepts and principles in the controlled classroom environment. This final component of the CBS VCS and certificate program aims to create contingencies for training applications of CBS.

The experiential-learning component may be the most variable (and important) component of the CBS VCS, as it contemplates not only the training of competencies but also the construction of opportunities that engage communities in tackling problems and demands that are of importance to them alongside the research interests of faculty and students, resulting in the development of cultural- and community-based applications of CBS (see also Cihon, Walker, et al., 2020, for a discussion of ethical considerations for culture and community applications of CBS). Thus, the experientiallearning activities may vary, from internships, to job opportunities outside the university, technical visits, translational or applied research in organizational and community settings, and more. In terms of settings, the work might be conducted with for-profit organizations, schools, hospitals, nongovernmental organizations, 
community associations, and so on. The main requirements are that students apply CBS in environments with a consideration of the multiple levels of organized complexity, and include an interdisciplinary partner.

Here we consider four examples of CBS-focused experiential-learning opportunities. The first is the detection of microcultural discrepancies between saying and doing, as an expression of the coherence between what is prescribed (in laws, codes of conduct, policies, etc.) and what is actualized. For example, the student may be trained to evaluate and intervene in settings with high rates of unsafe behaviors and may work toward the design of a culture of safety (e.g., Alavosius et al., 2017). A second example might include an analysis of the processes in subcultures and suboptimization. This kind of work includes observing and devising interventions to improve the optimization of processes within specific groups that form part of an organization, such as describing and developing training programs to improve learning in public settings (e.g., Ramos et al., 2016). A third example includes work in cultural architecture (e.g., constructing built environments that promote healthier and more active lifestyles or organizing contextual factors that promote community resilience in the face of climate disasters) and systems engineering (e.g., constructing organization and workplace policies to promote safety among employees or constructing school cultures that promote prosocial behavior among students, faculty, and staff). Students may be placed in positions to evaluate and design patterns of behavior and IBCs to increase and promote desirable cultural practices or decrease those that are problematic in organizations (e.g., Mayer, 1995) or communities (e.g., Bento \& Couto, 2021; Mayer, 1995). As a fourth example, the student might be trained in cross-sector and multidisciplinary approaches to addressing complex societal challenges (e.g., public health issues like climate change, racism, and violence can benefit from the combined expertise of behavior scientists and those well versed in sociology, social work, communication studies, conflict studies, ecology, public health, and more). When addressing wicked and superwicked problems, effective solutions rarely come from only one discipline, as these problems are not owned by only one discipline (Mattaini, 2019). Moreover, each of these examples emphasizes students' development of skills related to effective communication and leadership, as well as skills related to forming and sustaining interdisciplinary and community- or organizational-based partnerships.

An additional two examples derived from our recent work will be described in more detail to illustrate how students can develop competencies in forming and sustaining partnerships with local community sectors and organizations and in following their passion for social change. In the first example, graduate and undergraduate students in behavior analysis work with local high school students to develop leadership skills and to foster community engagement. In the second example, graduate and undergraduate students work within the university to improve the processes and practices of the college's advising department.

Behavior science has a longstanding tradition of collaborations with education and instructional design. In fact, Brethower's (1970) initial work in BSA and the development of the total performance system was influenced by his interest in instructional design and the creation of effective systems of instruction (cf. Brethower, 2008). Moreover, many behavior analysts working in educational settings have maintained an ecological perspective in their inter- and transdisciplinary scholarship and practice. Although numerous scientific and educational advances have 
resulted from this work, much of it has been grounded in applications of behavior science to work with individuals with developmental disabilities and populations with other special needs (cf. Schroeder, 1990). There have been far fewer examples of work with general education populations and even fewer examples of applications of behavior science that introduce students to the subject matter and its applications for social change outside of university settings. For the last 3 years, members of the CBS lab at UNT, including Cihon and Borba, have been collaborating with a local high school to do just that (Cihon et al., 2021).

Students of behavior analysis participating in the high school program for their experiential-learning component of the CBS coursework generally spend about $20 \mathrm{hr}$ per week designing, implementing, and evaluating a curriculum that supports the high school students in developing the target competencies related to behavior analysis, CBS, and their applications to social change. The students of behavior analysis work closely with both their faculty advisor and the high school classroom teacher in the actualization of these activities (Cihon et al., 2021). This latter relationship is essential to the CBS experiential-learning activities, as it encompasses the requirement that the experiential-learning activities are interdisciplinary. Students of behavior analysis also form close collaborations with their peers who are also participating in this practical training experience.

The goal of the high school program is to teach the high school students about behavior analysis and CBS through their applications to mitigating social issues like access to clean and safe drinking water or the reduction of our reliance on fossil fuels and adoption of alternative energy sources (Cihon et al., 2021). High school students are encouraged to become actively engaged leaders in their communities with course units designed to introduce them to topics such as prosocial behavior, identifying social problems, perspective taking, problem solving, basic principles of behavior analysis and CBS, and community-based applications of behavior science and CBS. Each year, the project has culminated in high school students developing either a matrix analysis (Biglan, 1995; Mattaini, 2013; see Fig. 2) or a force field analysis (Lewin, 1943; see Fig 3) focused on the identification of supporting and opposing practices (force field analysis) and/or the behaviors and practices of key actors and sectors, motivating contexts, consequences, and interdependencies among these contingencies that both sustain and may be modified to mitigate a social issue of their choosing (matrix analysis). Recently, the focus has been on the development of strategies and tactics to support the formation of community partnerships that promote opportunities for the high school students to take the knowledge acquired in the classroom to their local community.

In the coming year, high school students will be challenged to take leadership roles and engage in social action on social issues of their choosing. Although the social issues of interest cannot be specified at this time because the students have not yet identified what is important to them, past work examples (Figures 2 and 3) give some indication of the types of issues students are interested in addressing (e.g., littering and pollution, allocation of school funding, the opioid crisis, suicide). Once students have completed their solution-focused matrix analysis, we will support them in finding ways to start to alter the environmental controlling variables that will promote the desired behaviors and practices identified through their analysis. Past iterations of the high school program have encountered barriers in moving students into the implementation 

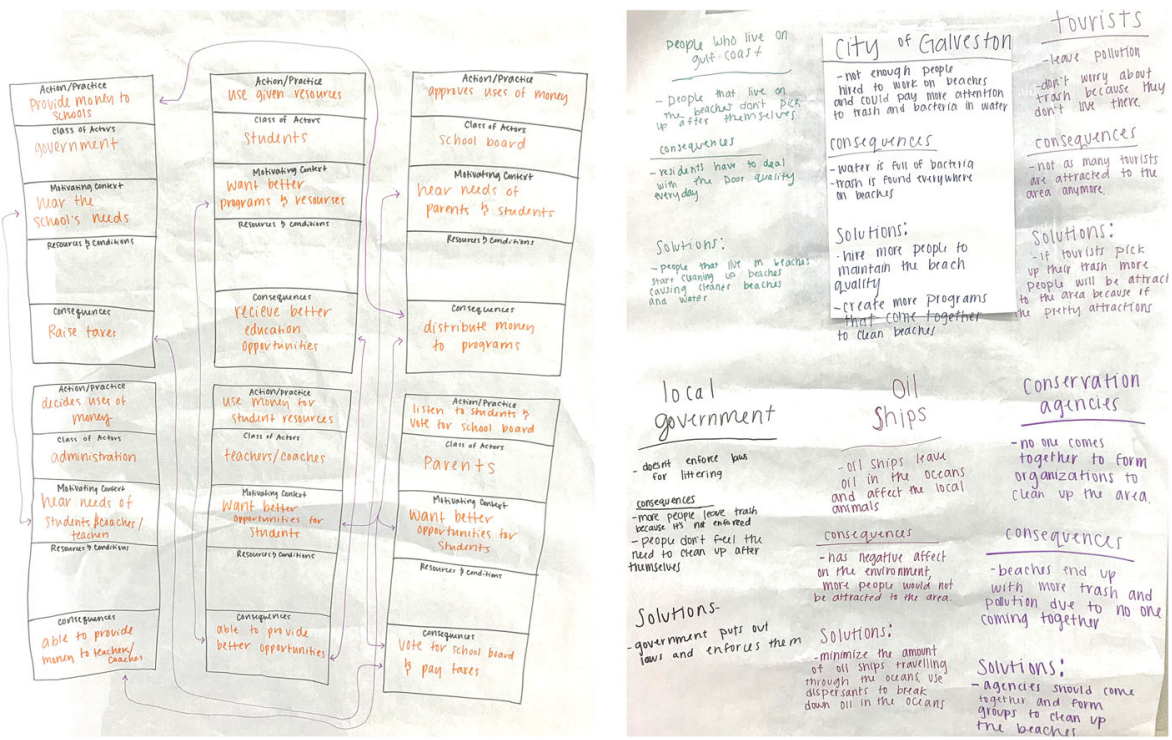

Fig. 2 Examples of the first cohort of high school students' matrix analyses. Note. The panel on the left addresses the school board's use of funds; the panel on the right explores ways to reduce littering on Galveston's beaches. Students identified the key actors, the practices they engage in that contribute to the problem, the contextual variables that evoke or set the occasion for these practices, and the consequences that sustain them. Students also conducted an analysis to determine how to shift the practices and behaviors, as well as how to change the environment to facilitate solutions. The students produced the analyses in fewer than three class sessions (less than $3 \mathrm{hr}$ ).

and social action phase of the program (i.e., the program's duration was limited to one semester, the full academic year program was interrupted due to the COVID-19 pandemic, and the most recent instruction was provided through Zoom, also due to the COVID-19 pandemic). Again, past work examples can give some insight into the types of actions students might take as they move into this phase later in the academic year. For example, the group of students interested in the school board's use of funds might begin by attending school board meetings and voicing their concerns or sharing their analysis. Alternatively, the students interested in addressing suicide rates might focus their efforts on a school-wide program that increases awareness and arranges both the motivating contexts and consequences for one or more of the driving forces such as increasing the frequency of students' checking on friends, acquaintances, and family members or encouraging those at risk to ask for help.

We are also developing a measurement system that allows us to quantify student engagement and learning throughout the program, as well as document student outcomes as they relate to the impact on the community more generally. This work is important to behavior science, CBS, education, and the communities more broadly, as we emphasize the importance of teaching students to become engaged community leaders who understand how to arrange contingencies that shape and maintain these important repertoires and strengthen their local communities.

It is beyond the scope of this article to describe all the idiosyncratic details of the collaboration; instead, the focus will be on how the program facilitates the competencies that correspond to the experiential-learning course for the CBS 


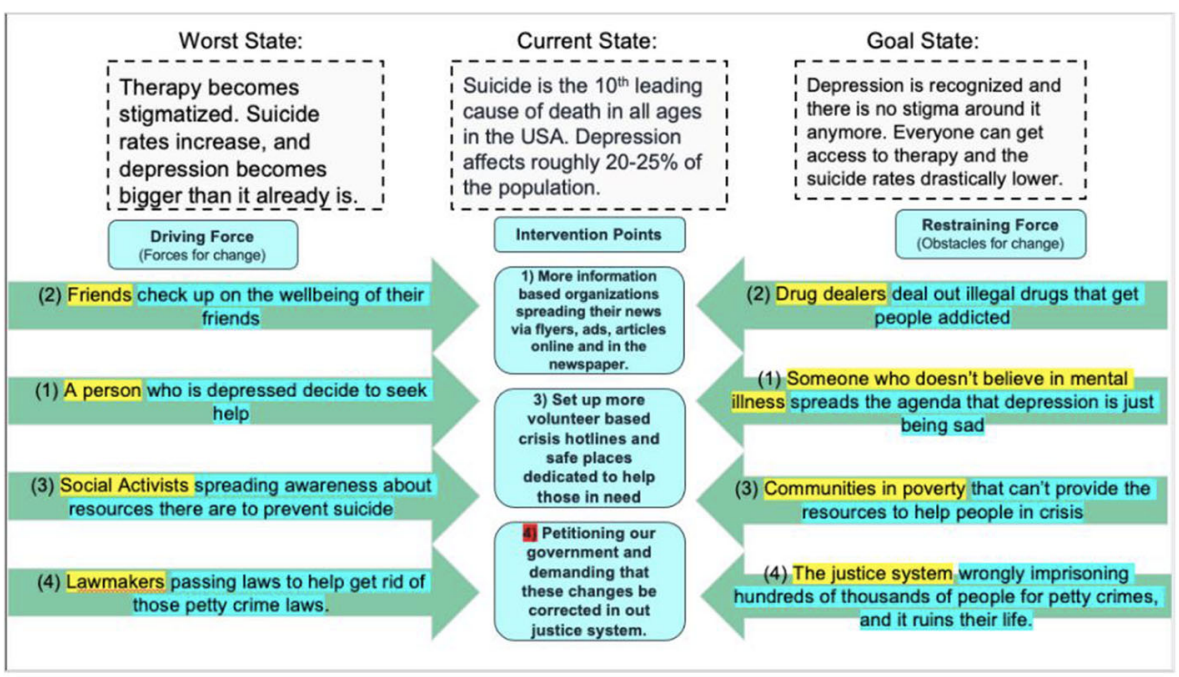

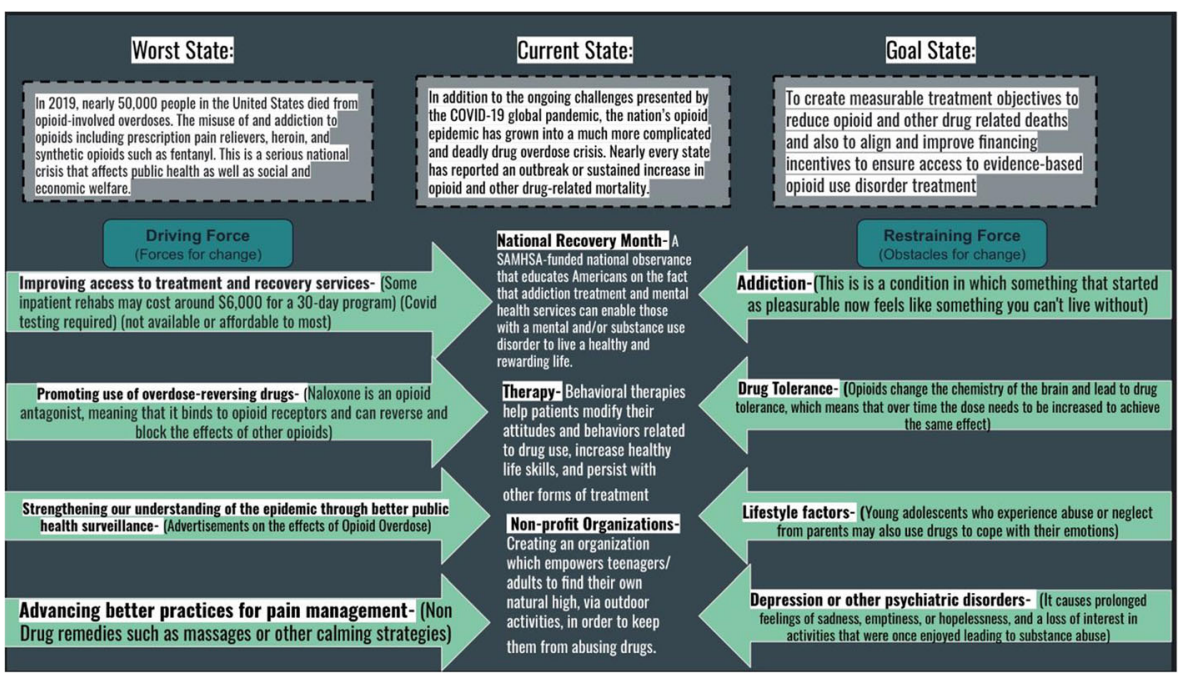

Fig. 3 Examples of the most recent cohort of high school students' force field Analyses. Note. The top panel addresses suicide as a leading cause of death; the bottom panel addresses the opioid epidemic in the United States. Students identified the current state of the problem of interest, the worst state possible, and the goal state. Next, students identified driving and restraining forces, as well as potential intervention points.

certificate. These include but are not limited to the following: (a) identify behavioral patterns that are relatively consistent over time, even though the members of the unit may be exchanged for new ones; (b) identify formal and informal intentions, goals, strategies, and other descriptions of the organization/cultural unit; (c) observe functional relations of behavior in context; (d) identify IBCs in possible conflict with expressed goals; (e) identify policy documents and the contingencies under which they are formulated (policy, politics, ideology, status, managerial preferences); (f) observe and identify whether behavioral patterns are flexible and thus match the complexity of the environment; and (g) apply techniques of the systematic observation of behavior in different contexts. In addition to the emphasis on community and system change from a 
behavioral perspective and the opportunity for interdisciplinary collaboration embedded in this practical experience, students of behavior analysis have the unique experience of learning about BSA while teaching BSA (Cihon et al., 2021).

In the second example, Cihon was asked to support the college's strategic planning effort, working specifically with the advising department in the College of Health and Public Service (HPS) to create visual depictions of the various processes that occur within the advising department to better understand both its structure and function. Graduate students in behavior science and undergraduate students enrolled in an organizational behavior management (OBM) course worked collaboratively with the advising department to address seven mutually developed goals.

The first goal was to identify the current process and system for new student orientation and registration. The participating students observed orientation activities in the fall of 2019 and created a process flowchart (see Fig. 4, top panel) depicting a student's experience during orientation. The second goal was to depict the general flow of the advising process HPS students were currently encountering. Graduate and undergraduate students met with several members of the advising team to determine the general sequence of activities and the core functions of academic counselors and advisors (those activities they complete during general advising meetings with students). The information gathered was used to develop two process maps (see Fig. 5) showing what new (Fig. 5, bottom panel) and current students (Fig. 5, top panel) experienced when working with advisors. The third goal was to identify the connections among all of the agents who were critical to the provision of services offered by the advising department. Students created a map showing the necessary interconnections including the structure of the advising department and how it is integrated into the larger system (i.e., macrosystem) of the college. It also depicted the general flow of communication among the various constituents (see Fig. 6). The fourth goal was to create a process map that portrayed the student-requested exception process. Graduate students worked with the director of student advising and student services to identify three types of student exceptions and to create a corresponding cross-functional process map. The fifth goal was to identify the role of work-study students in the advising department and to support the department leadership in maximizing their independence and utility. A team of undergraduate students, with the support of the teaching assistants for the OBM course, worked on this task with one of the work-study students. After reviewing the work-study student handbook and interviewing one of the work-study students, the team summarized the interview session and created a process map that depicted the work-study students' responsibilities that department personnel could use to pinpoint specific performance outcome measures to optimize student workers' performance. The sixth goal was to isolate the key features of the ongoing and dynamic communication process the advising department conducts each semester with all students. Participating students created a timeline illustrating the general sequence of communication between the advising department and all students over the course of a semester. The final goal was to assess the advising department's relationship to other student services and to depict the critical function of the advising department as a hub that connects students to numerous additional community- and university-based supports. The team created a diagram depicting the student services to which the advising department frequently connects students. 


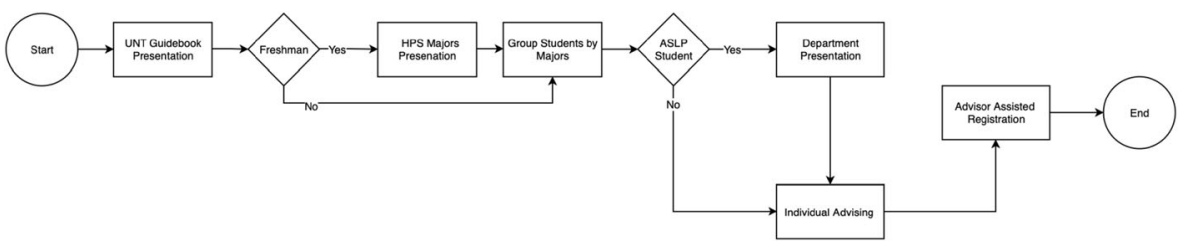

Fig. 4 Process flow chart for new student orientation. note. UNT = University of North Texas; HPS = Health and Public Service.

\section{Future Directions}

Collectively, the three components of the CBS VCS and certificate program aim to arrange contingencies to give students a solid background in behavior science while preparing them for new challenges facing the discipline and the current and future challenges facing humanity. The ABAI task force worked diligently to organize the CBS VCS and certificate program in such a way that it could stimulate and support the development of more university-based training programs in CBS, and to recruit and cultivate opportunities for students and aspiring behavior scientists to join the efforts to develop research and practice that might answer the challenges facing current and future generations. Nonetheless, and echoing the sentiments of so many behavior scientists, there is much more work to be done. Such work spans philosophical, theoretical, and conceptual considerations in CBS; basic research in CBS; cultural and community-based applications of CBS; and the education and training of behavior scientists.

\section{Philosophical, Theoretical, and Conceptual Considerations in CBS}

The origins of CBS are often traced to Skinner's early writings that focused on behavior as it occurs in its social environment (Skinner, 1953), the potential for the application of concepts and principles from behavior science to cultural design (Skinner, 1948a), and the selection of cultural practices that contribute to the evolution of culture (Skinner, 1981). Later work has been strongly influenced by Glenn's (2004) conceptualization of the metacontingency, centering on how it could enhance our understanding of
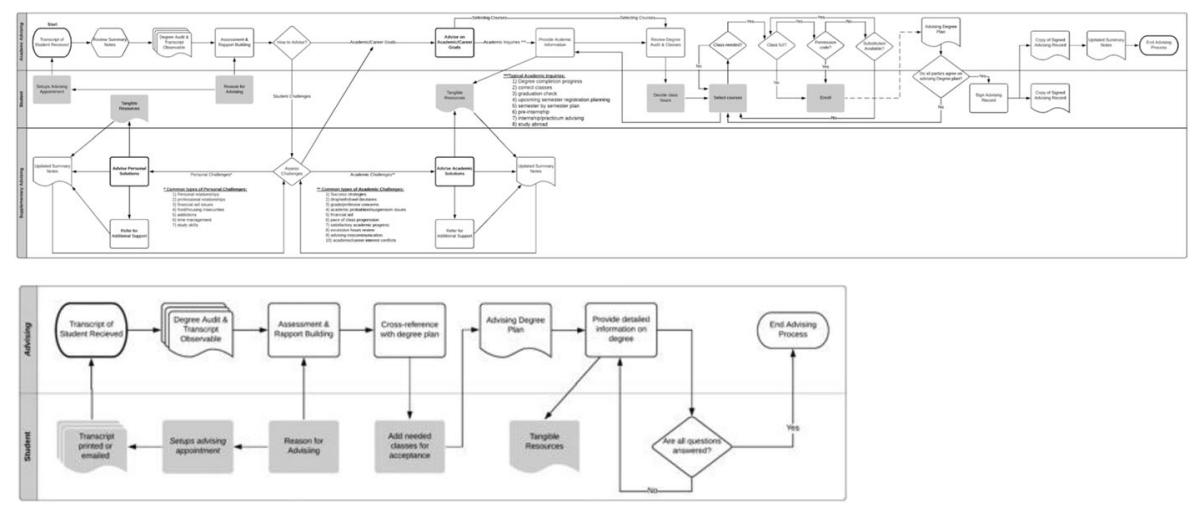

Fig. 5 Continuing (top panel) and prospective (bottom panel) student advising session process maps 


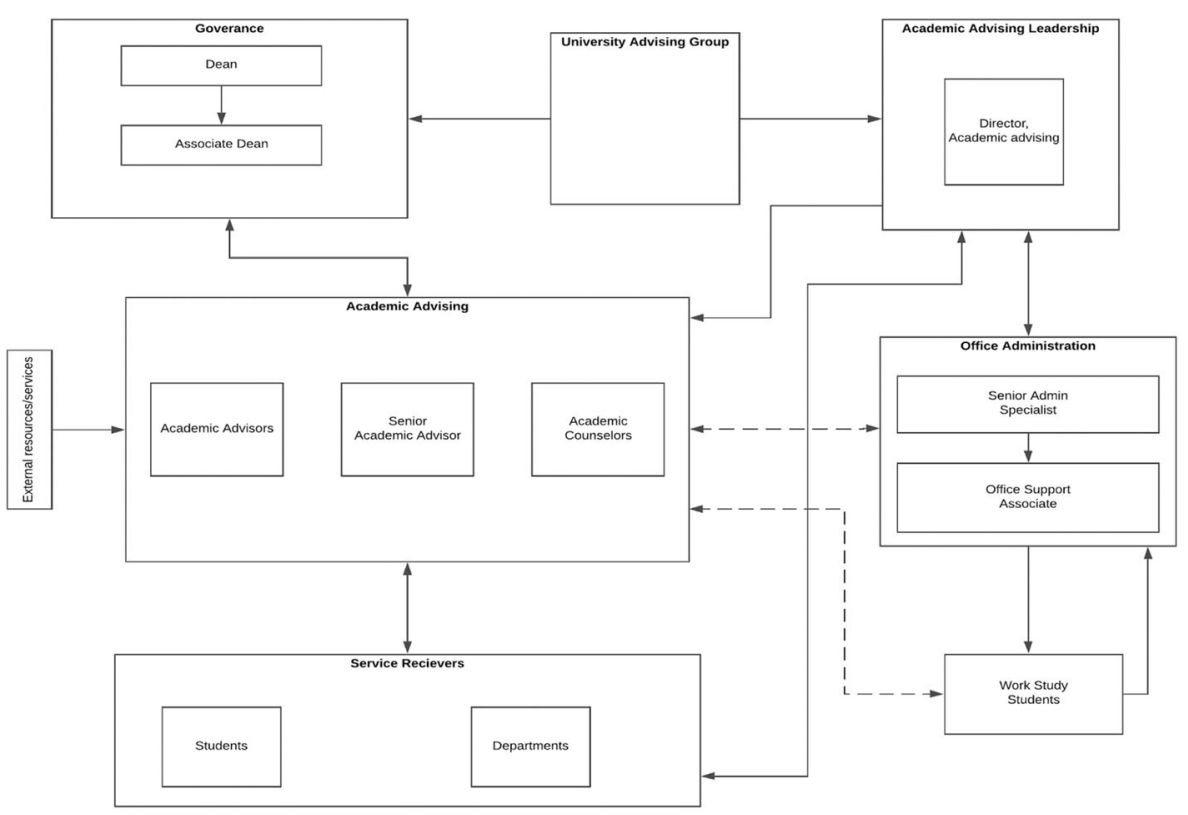

Fig. 6 Service Delivery Map

significant social issues in descriptions of behaviors and cultural practices contributing to the issue of interest and the operant and cultural contingencies that sustain them (e.g., Lamal, 1991; Malott \& Glenn, 2006; Todorov \& Lemos, 2020). Criticisms of the metacontingency are common (e.g., Branch, 2006; Marr, 2006; Mattaini, 2006; Zilio, 2019). In addition to reservations regarding the need for a new concept (beyond the operant) or third kind of selection (cultural selection) for a behavioral analysis of culture, points for expansion are drawn from assumptions and principles of systems science, like nonlinearity and holism (e.g., Mobus \& Kalton, 2015). Many have argued, for example, that the metacontingency simplifies the behavior and environmental controlling variables in a way that "something is lost when extrapolating the results produced with very simple behaviors to complex phenomena" (Cihon, Borba, et al., 2020 , p. 120). More recent works have extrapolated the possible intersection of systems and selection principles (e.g., Bento et al., 2020; Krispin, 2017, 2019; Mattaini, 2019, 2020), and discourse often revolves around the extent to which a systems-analytic framework should be adopted in CBS. Others have defined additional concepts to further explain certain phenomena (e.g., selection of cultures and cultural selection; Couto \& Sandaker, 2016; cultural milieu and group rule generation; Houmanfar et al., 2010; culturo-behavioral hypercycles; Krispin, 2019; cultural cusp; Malott, 2016), suggesting that there is still much to discover about how behavior science can contribute to solving some of the world's most pressing problems.

Some goals for those working in CBS related to philosophical, theoretical, and conceptual considerations might be to (a) further the discussion regarding the intersection of systems and selection principles and clarify the extent to which a systems-analytic framework should be adopted in CBS, (b) clarify and further refine various concepts in CBS, and (c) bridge conceptual advances in CBS with basic, translational, and applied research and practice. 


\section{Basic Research in CBS}

Although experimental researchers in behavior science have been tackling social behavior since the 1950s (e.g., Azrin \& Lindsley, 1956), the publication of Vichi et al. (2009) is generally cited as the first experimental study of the metacontingency. Focused on arranging conditions for the selection of the IBCs produced by two or more individuals working together in an experimental microculture or small group of participants and their resulting product (i.e., the culturant; Glenn et al., 2016; Hunter, 2012), such "experiments presented new strategies and tactics aimed to identify the basic processes surrounding cultural phenomena" (Cihon, Borba, et al., 2020, p. 121). In a recent review of basic laboratory studies on the metacontingency, Cihon, Borba, et al. (2020) identified 41 studies in English and Portuguese that had been published in peer-reviewed journals. Organized by experimental strategy, they found that the basic research on the metacontingency (a) confirmed the selective properties of cultural consequences on culturants; (b) replicated these effects across experimental strategies and tactics, in small groups of participants and/or microcultures consisting of two to four participants, and when culturo-behavior lineages are programmed by experimenters; (c) concluded that culturants are formed among participants when communication is restricted, though they are more readily formed when participants are permitted to communicate; (d) found that culturants are sensitive to aversive control and other parallels to operant conditioning (e.g., schedules of reinforcement, extinction); and (e) demonstrated that culturants are selected when operant and cultural consequences are both concurrent and nonconcurrent, as well as under conditions in which operant consequences of a higher magnitude are concurrent with the production of the cultural consequences (Cihon, Borba, et al., 2020).

Cihon, Borba, et al., 2020 also pointed out seven limitations of the basic research in CBS and areas that have yet to be explored given the recency of experimental work in CBS:

1. The experimental strategies and tactics employed thus far rely heavily on game theory, social psychology, and behavioral economics and thus rest on a specific set of assumptions that may restrict the information that can be obtained from such preparations.

2. The results of the studies reviewed did not always replicate within or across studies, suggesting the need to control for the effects of potential extraneous variables.

3. The experimental preparations did not account for all aspects of the social environment that are important for a complete behavioral account of culture, perhaps due "to the difficulty in arranging precise control over variables when the dependent variable (i.e., behavior) is also part of the independent variable (social and cultural contingencies) ... [and] the recursive relation between the behavior of interest and the contingencies arranged by humans themselves is difficult to isolate, let alone predict and control" (Cihon \& Mattaini, 2020b, pp. 2-3).

4. None had examined intersections with principles of systems science such as selforganization. 
5. The temporal scale of the microcultures may not have been long enough to fully capture culturo-behavioral lineages or the transmission of cultural practices across generations and the generally low number of participants working at the same time (i.e., never more than four).

6. The IBCs and the social interactions among the participants were often left out of the analyses, even though they were seemingly important to the study of behavior in its social environment.

7. There has been a growing emphasis on exploring basic operant principles at the cultural level.

In addition to addressing the aforementioned limitations of the basic research and areas that have yet to be explored in CBS, basic research in CBS might focus on developing clear demonstrations of work in CBS that describes the conditions under which we need to go to the lab and the conditions under which we need to be immersed in communities, organizations, and so on (Cihon, Borba, et al., 2020). Such work in this area might center on (a) the identification of "mechanisms by which culture and cultural practices are formed, maintained, and transmitted," (b) "the evaluation of new concepts and interpretations of culture and cultural phenomena [when] proposed," and (c) the exploration of phenomena that do not allow for "experimental manipulation of controlling variables .... in the natural environment ... [and in] situations in which it is not feasible or ethical to withdraw effective interventions in order to demonstrate functional relations in the communities" (Cihon, Borba, et al., 2020, pp. 142-143).

\section{Cultural and Community Applications of CBS}

Perhaps one of the biggest challenges facing scholars and practitioners in CBS is the dearth of work in cultural and community applications of CBS. However, engaging in this work will require much more extensive efforts in CBS in translational research and in research conducted in cultural and community settings. Building from examples of nonlaboratory work in CBS centered on descriptions of behaviors and cultural practices contributing to the issue of interest and the operant and cultural contingencies that sustain them (e.g., Aspholm \& Mattaini, 2017; Carvalho et al., 2017; Malott \& Glenn, 2019), natural experiments (e.g., Todorov, 2009), and the work of behavioral community psychologists (e.g., Watson-Thompson, Francisco, et al., 2020), one goal for researchers and practitioners working in this area might be to bridge conceptual and experimental work to organizational, institutional, and community settings. Employing a participatory-action research methodology, the focus of this work can emphasize developing applications of CBS that support the realization of more socially-, economically-, and environmentally- just settings.

\section{Education and Training of Behavior Scientists}

Education, the provision of effective educational practices, and equitable access to education have long plagued both behavior scientists and society at large. Education has been shown to be effective in raising awareness about important topics and supporting the development of an informed and engaged society, and is a protective factor that "reduces mortality twice - directly, and through higher earnings" (Jacob, 
2012, p. 126). Effective educational practices and equitable access to education more generally may serve critical roles in helping to mitigate some of the world's most pressing problems. Much of Cihon's research related to behavior analysis and education has focused on developing effective instructional programs and strategies to introduce students (high school, undergraduate, and graduate) to the potential of behavior science and CBS in creating and sustaining more socially-, economically-, and environmentally- just communities and settings. A related goal of this work has been training aspiring behavior analysts to develop, implement, and evaluate the aforementioned instructional programs and strategies.

Relatedly, the future of behavior science and its potential to play a key role in contributing to lessening the burden of society's most difficult challenges depend, in part, on today's students of behavior science. Currently, aspiring behavior analysts are ready and motivated to take on this challenge. They see the problems their generation and future generations are facing. They also see that the problems are largely caused by human behavior. Students of behavior science want to better understand the recursive relations between human behavior and the networks of contingencies that make up our social and cultural environments and sectors' interdependencies. They want to learn how behavior science and CBS can improve their efforts to organize and promote strategic social action.

Thus, another important goal for future work in CBS is to both ignite and foster students' interests in CBS. Expanding from a rich history in behavioral approaches to education (e.g., Evans et al., 2021; Keller, 1968; Skinner, 1968), this work can emphasize the development of strategies to introduce students of behavior science to the diversity of thought embodied in CBS in their coursework, research, and practical experiences.

\section{Sustaining and Supporting a Focus on CBS}

Work in CBS is not easy, but it can be done, especially if it is done with the right supports and focuses on developing the critical repertoires for students and aspiring behavior scientists, such as those outlined in the CBS VCS and certificate program. Institutions that are developing such programs might benefit from arranging supportive practices that might include inter- and transdisciplinary collaboration, the facilitation of mentorship activities, and the development of communities of practice (Cihon, Becker, et al., 2020). CBS requires the analysis of the contingencies sustained in our social institutions. Holland (1978) noted that

it is these systems of contingencies that determine our behavior. If the people of a society are unhappy, if they are poor, if they are deprived, then it is the contingencies embodied in institutions, in the economic system, and in the government which must change. It takes changed contingencies to change behavior. If social equality is a goal, then all the institutional forms that maintain stratification must be replaced with forms that assure equality of power and equality of status. If exploitation is to cease, institutional forms that assure cooperation must be developed. Thus, experimental analysis provides a supporting rationale for the reformer who sets out to change systems. (p. 170) 
Achieving these goals requires that students and aspiring behavior scientists develop not only the key repertoires and competencies aligned with the CBS VCS and certificate program but also the key repertoires for the ethical applications of CBS. Cihon, Walker, et al. (2020) described some of these, including (a) forming collaborations that are both interdisciplinary and formed with members of the community; (b) developing perspective-taking repertoires related to respecting and valuing the diverse perspectives of both the individuals in the target community and the different groups of individuals in the target community; (c) developing and fostering cultural humility, which is key to developing effective collaborations and to taking multiple perspectives; and (d) creating interventions, measures, and so on that are sustainable by the community and its members, even in the absence of outside change agents.

The advice Keller gave when he was asked what advice he had for behavioral educators is relevant to those faculty and institutions that may be pursuing the development of the CBS VCS and certificate program. Recounting some advice that Skinner once gave him, Keller suggested the following (as quoted in Heward \& Dunne, 1993):

Keep working in a small way, keep on promoting good things. When you see something good taking place, reinforce it if you can. When you see something going in the right direction, praise it. Anytime you see a model school that looks as if it's applying good behavioral principles, give it your support. Every time you hear of somebody doing something good, drop him or her a line and say, "thank you very much for what you're doing." I believe the process is something like shaping. Don't expect many big changes to take place. There's not going to be any revolution. But maybe, if we all keep on nibbling, we can change education. I don't know of any other way. (p. 343)

To address the challenges facing humans now and in the next 50 years, we need to come together as a community, supporting one another's efforts toward mitigating complex social issues, within our own science, communities, and globally. After all, we are all in this together. And if we keep nibbling, together, as faculty, students, scientistpractitioners, researchers, and community members, we can do more than imagine a more just and equitable world; we can create it.

Funding This study was not conducted with support from any funding mechanism.

\section{Compliance with Ethical Standards}

Conflict of interest All authors declare that they do not have any conflicts of interest.

Ethical approval All procedures performed in studies involving human participants were in accordance with the ethical standards of the institutional and/or national research committee and with the 1964 Helsinki declaration and its later amendments or comparable ethical standards. 


\section{Appendix}

Table A1 Objectives and Competencies in Foundational Knowledge in Behavior Science
Course objectives
Identify the main concepts of behavior analysis
Analyze behavior using such concepts
Discuss the implications of these concepts to experimental and applied research

\begin{tabular}{ll} 
Item & Competencies \\
\hline $\begin{array}{l}\text { Selection by consequences (phylogeny, } \\
\text { ontogeny, and culture) }\end{array}$ & $\begin{array}{l}\text { Identify each level of selection } \\
\text { Describe the relation between each level } \\
\text { Identify the subject matter of behavior analysis in each level } \\
\text { Relate levels of selection to different notions of cause in psychology } \\
\text { Reflexes and respondent behavior }\end{array}$ \\
& $\begin{array}{l}\text { Recognize the main characteristics of respondent learning } \\
\text { stimulus, unconditioned response, habituation, etc.) }\end{array}$ \\
& Describe experimental work related to these concepts \\
& Describe the importance of these concepts to applied settings
\end{tabular}

Consequences of behavior: reinforcement Recognize the main characteristics of operant learning (positive and negative)

Define the main topics related to operant behavior and its control by reinforcement (positive reinforcer, negative reinforcer, extinction, etc.)

Differentiate between operant and respondent behavior

Discuss critically the benefits and problems of control by reinforcement contingencies

Consequences of behavior: punishment (positive and negative)

Define the main topics related to operant behavior and its control by punishment (positive punishment, negative punishment, etc.)

Differentiate between control by reinforcement and punishment, especially relating it to negative reinforcement

Discuss critically the benefits and problems of control by punishment contingencies

Describe experimental work related to these concepts

Describe the importance of these concepts to applied settings

Schedules of reinforcement and choice Identify different schedules of reinforcement

Describe complex schedules of reinforcement

Describe experimental work related to these concepts

Describe the importance of these concepts to applied settings

Basic principles of stimulus control: discrimination and generalization

Define stimulus control and its relation to operant behavior

Identify discrimination processes in operant behavior

Identify generalization processes in operant behavior

Describe experimental work related to these concepts

Describe the importance of these concepts to applied settings

Equivalence stimuli classes and relational Identify different cases of stimulus control: equivalence stimuli learning and relational learning

Describe differences between the different operations or processes in stimulus control

Describe experimental work related to these concepts

Be able to understand the main theoretical debate involving the naming hypothesis, relational frame theory, and equivalence relations based on direct-acting contingencies

Describe the importance of these concepts to applied settings

Differentiate stimulus control from motivating function 
Table A1 (continued)

Course objectives

Identify the main concepts of behavior analysis

Analyze behavior using such concepts

Discuss the implications of these concepts to experimental and applied research

Item Competencies

Motivating operations (establishing operations, abolishing operations)

Social behavior

Verbal behavior

Rule-governed behavior
Define and identify different types of abolishing and establishing operations

Identify the effects of motivating operations on reinforcement and discriminative stimuli

Identify motivating operations related to conditioned or unconditioned reinforcement

Describe experimental work related to these concepts

Describe the importance of these concepts to applied settings

Differentiate social behavior from nonsocial behavior

Define social stimuli and social reinforcement

Identify social behavior as an interlocking behavioral contingency

Identify procedures to study social behavior

Describe experimental work related to these concepts

Describe the importance of these concepts to applied settings

Differentiate verbal behavior from nonverbal behavior

Categorize verbal behavior based on functional categories and identify different contingencies in verbal operants (tact, mand, autoclitics, etc.)

Identify procedures to study verbal behavior

Debate verbal behavior as social behavior

Describe experimental work related to these concepts

Describe the importance of these concepts to applied settings

Identify rule-governed behavior in the context of operant analysis Differentiate rule-governed behavior and behavior shaped directly by contact with nonverbal contingencies

Identify procedures to study rule-governed behavior

$\mathrm{Be}$ able to identify divergences in the analysis of rule-governed behavior and how they are related to simple or conditional stimulus control and motivating operations

Describe experimental work related to these concepts

Describe the importance of these concepts to applied settings 
Table A2 Objectives and Competencies in Cultural Behavior Systems Science

\section{Course objectives}

Explain the conceptual development and technological application of behavioral systems analysis (BSA) Describe the conceptual, methodological, and technological strengths and weaknesses associated with this approach

Integrate themes and topics in behavior analysis that may contribute to the conceptual, methodological, and technological development of BSA

Item
Introduction to organizational behavior
management, BSA, and systems theory

Selection and cultural change

Complexity and emergence

Transdisciplinary considerations on complexity and systems

\section{Competencies}

Define (i.e., state the main components of) organizational behavior management

Define (i.e., state the main components of) general system(s) theory

Define (i.e., state the main components of) BSA

Differentiate among organizational behavior management, general system(s) theory, and behavioral systems analysis

Name, define, and describe the three kinds of selection, including the units of analysis and how the selection occurs over time

Describe how each kind of selection is necessary but different from each of the other kinds of selection

Define and differentiate between and among an individual response, a behavioral lineage, and a cultural (culturo-behavioral) lineage and provide examples of each

Define (including the critical components and the relations between the components) and differentiate between and among the concepts of the metacontingency, the macrocontingency, and the cultural cusp

Define and differentiate among "process," "content," and "procedure" in operant contingencies and metacontingencies

Describe at least two ways in which one might produce cultural change

Describe the types of selection processes that have been proposed (including the units that are selected and the contingency arrangements) to be involved in cultural evolution and the various perspectives with respect to these processes

Define systems, complex systems, complex adaptive systems, and self-organizing systems

Describe and analyze the concepts of emergence and complexity in the context of cultural and systems evolution and large-scale change

Describe some of the challenges in designing complex systems and in predicting and producing large-scale change

Summarize and provide a critical analysis of some of the proposed strategies for promoting large-scale change

Describe the implications of theories (social-ecological systems approach, system dynamics, exploratory modeling and analysis, institutional economics analysis of social dilemmas) that consider or discount the interdependencies among constituents in complex systems 
Table A2 (continued)

\section{Course objectives}

Explain the conceptual development and technological application of behavioral systems analysis (BSA)

Describe the conceptual, methodological, and technological strengths and weaknesses associated with this approach

Integrate themes and topics in behavior analysis that may contribute to the conceptual, methodological, and technological development of BSA

Item

Communication and cultural change

Leadership and cultural change

\section{Competencies}

Describe the approaches to modeling (predictive modeling, exploratory modeling and analysis), the strengths and limitations of each, and the types of research questions that can be addressed by each

Explain how different perspectives within systems theory have been used to understand global societal challenges (wicked problems), including the strengths and limitations of each (particularly with respect to systems' boundaries and prediction)

Compare and contrast transdisciplinary perspectives on complexity and systems with BSA perspectives on complexity and systems, particularly related to cultural, societal, and organizational change

Describe the form and function that communication typically serves in the organizational setting, including examples of communication in the context or form of communication networks, rules, rumor, leadership, and so on

Explain what relational frame theory adds to the analysis of cultural practices with a specific focus on derived relational responding, rules, and the associated effects on the behavior of individuals, as well as "interlocked behaviors"

Describe the difference between sociological and psychological events and what the implications of this are for culture and the metacontingency more specifically

Define (including the critical components and the relations between the components) and differentiate between and among the components of the expanded (five-term) metacontingency

Describe the rationale, method, and findings of some of the experimental work that has explored the role of verbal behavior in understanding the cultural practices of organizations

Define leadership from a behavioral perspective

Describe the key functions of leadership, including the characteristics of good leaders, particularly with respect to communication; the variables that promote effective leadership; and how leadership entails shifts in metacontingencies

Explain how leaders promote organizational values and how leaders can promote prosociality, balancing financial and social capital and contingencies

Summarize the key findings from behavior-analytic efforts to understand leadership and the behaviors and related contingencies that leaders might exhibit to produce cultural change that promotes the well-being of society 
Table A2 (continued)

\section{Course objectives}

Explain the conceptual development and technological application of behavioral systems analysis (BSA)

Describe the conceptual, methodological, and technological strengths and weaknesses associated with this approach

Integrate themes and topics in behavior analysis that may contribute to the conceptual, methodological, and technological development of BSA

Item Competencies

Selection and organizational change

Cultural contingencies in organizations: functional assessment and process analysis
Describe the role of selection (behavioral and cultural), the corresponding units of analysis, and the conditions under which each is most appropriate in the context of organizations

Describe the relations between behavioral contingencies, interlocking behavioral contingencies, metacontingencies, and the total performance system

Define and identify the relations between the organization, the system, and the subsystem and compare and contrast them

Describe how the boundaries of a system or organization are identified

Describe the different types of complexity and the relations between them and explain how complexity affects an organization

Describe the implication of growth in management and how that relates to the interlocking behavioral contingencies at lower levels

Compare and contrast BSA/performance systems analysis and organizational behavior analysis

Summarize how applied behavior analysis and organizational behavior management employ utopian thinking in their practice and describe the four recommendations made by Abernathy (2009) that could improve the implementation and sustainability of a "behaviorist utopia" within the context of existing organizations.

Perform a total performance system analysis of an organization

Prepare a summary of the administrative structure and a department-function analysis for an organization

Prepare a detailed analysis (including a detailed process map and units of measurement) of at least one process within an organization that includes (a) process identification, (b) scope, (c) subprocesses, (d) units, (e) general tasks, (f) aggregate products, (g) participants, (h) uniqueness, and (i) duration

Prepare a contingency analysis and task analysis for one performer within an organization

Identify, within an organization, an existing contingency, a performance management contingency that could change that contingency, the corresponding interlocks, and the measures that will allow them to determine if there was a shift in performance

Describe, from a BSA perspective, the three repertoires and the contingencies associated with the promotion of each that are necessary to sustain effective resistance campaigns 
Table A2 (continued)

\section{Course objectives}

Explain the conceptual development and technological application of behavioral systems analysis (BSA)

Describe the conceptual, methodological, and technological strengths and weaknesses associated with this approach

Integrate themes and topics in behavior analysis that may contribute to the conceptual, methodological, and technological development of BSA

Item Competencies

Cultural contingencies in organizations: the behavioral systems engineering model

Applications to complex systems: ecological analyses, Part 1

Applications to complex systems: ecological analyses, Part 2
Identify, define, and provide the rationale for at least one measure for each component in their total performance system analysis

Summarize the rationale, method, and stages of the behavioral systems engineering model and describe how the model can be used to produce organizational change

Describe external complexity and internal complexity and what the internal and external selection practices might be with respect to how aggregate products and interlocking behavioral contingencies are selected in organizations and industry

Differentiate behavioral cusps from cultural cusps and differentiate cultural cusps from cultural incidents

Construct an analysis of an organizational/community process or a set of interrelated processes or functional units based on Malott's (2003) behavioral systems engineering model

Explain how behavioral systems science is ecological and selectionist, how ecological strategy differs from the traditions of behavior analysis, and how ecological strategy might place cultural systems science as a specialty in ecological science

Summarize the process/method, the uses, and limitations of (a) feedback-guided analysis and (b) Dyball and Newell's (2015) "cultural adaptation template"

Describe the three types of cultural-analytic scholarship, their contributions, and their limitations

Explain why new analytic tools are necessary for those engaged in cultural systems science and describe some of the tools that might be necessary

Differentiate between "collective one-time actions" and "persistent cultural practices" and describe why these constitute the behavioral system's dynamics

Describe the general process one may use "to influence the values or actions of a larger population" (Mattaini, 2013, p. 259), the goals of this process, the phenomena for which this process is appropriate, and how the process can be adapted when the analysis shifts to that of behavioral systems

Describe the conditions under which shifts in metacontingencies are insufficient to create large-scale change and describe the types of analyses that might be useful under those conditions

Summarize how BSA and constructional methods can contribute to meaningful change as they relate to youth violence 
Table A2 (continued)

\section{Course objectives}

Explain the conceptual development and technological application of behavioral systems analysis (BSA)

Describe the conceptual, methodological, and technological strengths and weaknesses associated with this approach

Integrate themes and topics in behavior analysis that may contribute to the conceptual, methodological, and technological development of BSA

\section{Item}

Creating solutions to social problems: sustainability and climate change a

Creating solutions to social problems: common pool resources a

Creating solutions to social problems: experimental microcultures ${ }^{\text {a }}$

\section{Competencies}

Generate a diagram that depicts the likely interdependencies between several sectors within a community or organization that influence collective outcomes

Generate a matrix illustrating proposed practices within multiple sectors that could help construct and sustain a desirable cultural practice among a target group and provide an ecological rationale for their analysis

Describe the processes embedded in and the advantages of applying language-based psychological intervention methods to sustainability issues

Describe the role of organizations in affecting behaviors contributing to climate change and describe systems-level interventions that could be employed and researched

Explain the rationale, general strategy, and supporting science for culture-based solutions that might lead to a more promising future with respect to climate change

Describe how climate change is a "superwicked problem" and note how policy-change initiatives could be made more effective if a path-dependent, applied, forward-reasoning approach were employed

Identify how culture-based solutions to climate change intersect with path-dependent and apply forward-reasoning approaches to policy intervention as related to climate change

Describe Hardin's tragedy of the commons

Describe Ostrom's work related to remediating the tragedy of the commons

Draw parallels between Ostrom's work and a culturo-behavioral systems science perspective

Describe current (and potential) efforts from behavioral scientists at employing a culturo-behavioral systems science perspective to research variables derived from Ostrom's work at governing the use of common pool resources

Explain game theory, the Nash equilibrium, and the way experimental games are used to measure preference, particularly social preference, and the advantages and limitations of doing so especially as compared with field experiments

Describe the prisoner's dilemma game and at least two additional experimental games, including the following information: (a) the definition of the game, (b) the predictions game theorists make regarding the game, (c) the procedural variations, and (d) the way the findings are interpreted 
Table A2 (continued)

\section{Course objectives}

Explain the conceptual development and technological application of behavioral systems analysis (BSA)

Describe the conceptual, methodological, and technological strengths and weaknesses associated with this approach

Integrate themes and topics in behavior analysis that may contribute to the conceptual, methodological, and technological development of BSA

Creating solutions to social problems: community health and social justice a

Creating solutions to social problems: activism, advocacy, and accompaniment ${ }^{\mathrm{a}}$
Describe the primary preparations, experimentally arranged contingencies, and other important methodological distinctions in research on cultural selection processes

Describe the major conclusions that can be drawn from the extant literature based on cultural selection processes and the limitations of this research

Comment on the need to differentiate between the effects of individual operant-level contingencies and cultural consequences contingent on the culturant, as well as on the work that has attempted to draw parallels between operant-level selection and cultural selection

Explain how the criteria for applied behavior analysis align with applying behavior analysis to community-level research

Describe the five values indicative of developing collaborative relations between behavioral researchers and participants

Describe the four values and principles that underlie community needs and resource assessments

Describe the five values that should guide community-based interventions and dissemination efforts for behavioral research conducted in community settings

Describe how mentalism and attribution theory more specifically might impede social justice efforts and explain why behavior analysis offers a constructive alternative to mentalism as it relates to social justice, prejudice, racism, and discrimination more generally

Provide an example of a community needs and resources assessment and develop a community-based intervention focused on social justice, including a description of how the information gathered from the assessment informs the intervention

Describe and provide examples of the role nonprofits and advocacy organizations can serve in reducing negative externalities

Describe and provide examples of the contingencies that shape the practices of advocacy groups

Explain the set of policies described by Biglan (2009) that can sharpen the contingencies that influence advocacy organizations such that they can act effectively in the interest of public well-being

Examine several case studies detailing activism and advocacy efforts led or described by behavior analysts and summarize the critical features of each

Describe the contingencies they would arrange to lead an activism and/or advocacy effort for a cause of their choosing 
Table A2 (continued)

\section{Course objectives}

Explain the conceptual development and technological application of behavioral systems analysis (BSA)

Describe the conceptual, methodological, and technological strengths and weaknesses associated with this approach

Integrate themes and topics in behavior analysis that may contribute to the conceptual, methodological, and technological development of BSA

Item Competencies

Developing solutions for organizational problems: the total performance system ${ }^{\text {a }}$

Developing solutions for organizational problems: human performance technology and organizational culture ${ }^{\text {a }}$
Define and distinguish between rule-governed behavior and contingency-shaped behavior in organizations, outlining Abernathy's free-operant approach

List the components and subcomponents of Abernathy's (2003) total performance system, list and describe the main principles of effective behavior-change measures, and list the main consequential variables identifying which one is essential during the beginning stages of the implementation of the total performance system

Compare and contrast different types of leadership and managerial styles in organizations with respect to how they affect performance

Compare and contrast Abernathy's and Malott's behavioral systemic approaches

Describe the key features of the performance chain model and the six-boxes model of behavior influence

Differentiate behavior from accomplishments and describe why "work outputs" is the term preferred in place of "accomplishments"

Explain how cultural values influence performance expectations

Describe how to use the Behavioral Systems Analysis Questionnaire to guide performance within an organization

Explain how the Critical Practices Cultural Audit can be used to align an organization's culture and performance with customer value and describe the steps one needs to take to perform and implement such an analysis

List and describe the steps in the human performance technology approach to BSA

\footnotetext{
${ }^{a}$ Items designed to be rotating special topics that can be organized in any combination that complements the faculty member's or students' interests.
} 
Table A3 Objectives and Competencies for Experiential Learning

Course objective

The student should be trained with a focus on observing the coherence between saying and doing as an expression of the coherence between strategy and culture.

Item

The detection of microcultural discrepancies of saying and doing

Course objective

The student should be able to reveal cultural suboptimizations and subcultures

Item

Subcultures and suboptimization

\section{Competencies}

Identify behavioral patterns that are relatively consistent over time, even though the members of the unit may be exchanged for new ones

Identify formal and informal intentions, goals, strategies, and other descriptions of the organization/cultural unit

Observe the functional relations of behavior in context

Identify interlocking behavioral contingencies in possible conflict with expressed goals

Analyze social behavior research

Identify behavioral patterns that are consistent over time, even though the members of the unit may be exchanged for new ones

Know Skinner's (1957) verbal operants

Understand the basics of relational frame theory

Know and use techniques of the systematic observation of behavior in different contexts

Describe the main components of the target observation scenario and the possible networks of metacontingencies

Formulate a short interview with a member of the management team and members of other teams involved on the main objectives of the sector, actions, and results evaluated by them

Describe microcultural discrepancies of saying and doing in a system (e.g., science, education, family, church, or government system)

Describe the concepts of culture and microculture from the perspective of behavior analysis

Describe verbal networks

Propose a dynamic diagram on an informational platform for a manager in tracking discrepancies between saying and doing

Propose a dynamic diagram in an information platform for a manager for the monitoring of cooperative networks ([interlocking behavioral contingencies $\rightarrow$ aggregate products $] \rightarrow$ selective environment / cultural consequences)

\section{Competencies}

Identify how resources match the outcome of investment (e.g., how "one-click solutions" might outcompete huge investments)

Identify the flow of tangible resources, social reinforcement, and technology supporting the processes leading to aggregate products

Identify the concepts used in the study of cultural phenomena such as metacontingency, culturo-behavioral lineage, macrocontingency, macrobehavior, and cultural cusp

Know and use the behavioral systems approach - the metacontingency hierarchy in a network

Identify the main values present in verbal networks

Depict a flow of key interactions between the main tasks in a system

Know about experimental and quasi-experimental research designs 
Table A3 (continued)

Course objective

By tracing the information and influence flow and identifying network structures, the student should be able to model alternative ways to disseminate information and reinforce cultural practices

Item

Cultural architecture and systems engineering

\section{Competencies}

Identify possible conflict of interests and how they may be related to the dynamics of the system

Negotiate solutions by showing consequences "for the common good"

Elicit and map the structure of complex systems and relate those structures to their dynamics

Apply tools to modeling and simulations of complex systems and procedures for improving models

Identify possible conflicts of interests and how they may relate to the dynamics of the system

Understand and analyze common pool resources (natural or man-made)

Identify and analyze the potential points that may result in the tragedy of the commons or that may cause risks to common pool resources (if any)

Identify areas of knowledge represented within the system that are involved in leadership or are of strategic importance

Seek complementarity in negotiating solutions

Identify and analyze external variables that compete for expected outcomes

\section{Course objective}

By using the growing body of behavioral insights, one might debias this by moving away from sometimesunrealistic assumptions of rationality to discover the actual behavior of individuals through problem identification, behavior analysis, experimentation, and trialing that tests multiple policy responses at a smaller scale to determine the best course of action in a cost-effective manner

Item

Cross-sector and multidisciplinary approaches

\section{Competencies}

Understand the borders between legal, political, and behavioral regulations in terms of complex societal challenges

Present documentation for evidence

Have active dialogue with actual citizens and stakeholders

Report failed and successful projects

Identify and define the problem

Determine the policy level of the project

Decompose the policy problem into behavioral insights

Strategies for behavioral change: sun small scale experiments and testing and embed behavior in cultural practices

Use the functional analysis of choices in sectors of government in which rational theory establishes a relationship between giving greater knowledge to the citizen and this results in better choices

Understand the borders between legal, political, and behavioral regulations

Be able to present documentation for evidence

Have active dialogue with current citizens and stakeholders

Report failed and successful projects

Identify, evaluate, and use strategies

Understand the parallel between concepts of behavior analysis in the study of cultural phenomena and the analysis of the social sciences, economics, law, and/or other subareas of psychology 


\section{References}

Abernathy, W. B. (2003). Creating a high performance organization through a "free operant workplace." Performance Systems Analysis. Cambridge Center for Behavioral Studies. http://store.behavior.org/ resources/396.pdf

Abernathy, W. B. (2009). Walden Two revisited: Optimizing behavioral systems. Journal of Organizational Behavior Management, 29, 175-192. https://doi.org/10.1080/01608060902874567

Alavosius, M. P., \& Houmanfar, R. A. (2020). Global warming: Analysis of behavior and organizational practices on climate change. In T. M. Cihon \& M. A. Mattaini (Eds.), Behavior science perspectives on culture and community (pp. 221-256). Springer.

Alavosius, M. P., Houmanfar, R. A., Anbro, S. J., Burleigh, K., \& Hebein, C. (2017). Leadership and crew resource management in high-reliability organizations: A competency framework for measuring behaviors. Journal of Organizational Behavior Management, 37(2), 142-170. https://doi.org/10.1080/ 01608061.2017 .1325825

Alessi, G. (1987). Generative strategies and teaching for generalization. The Analysis of Verbal Behavior, 5 , 15-27. https://doi.org/10.1007/bf03392816

Ardila-Sánchez, J. G., Cihon, T. M., Malott, M. E., Mattaini, M. A., Rakos, R. F., Rehfeldt, R. A., Richling, S. M., Roose, K. M., Seniuk, H. A., Stewart, D., \& Watson-Thompson, J. (2020). Collective editorial: Ten guidelines for strategic social action. Behavior and Social Issues, 29, 15-30. https://doi.org/10.1007/ s42822-020-00038-8

Aspholm, R. R., \& Mattaini, M. A. (2017). Youth activism as violence prevention. In P. Sturmey (Ed.), The Wiley handbook of violence and aggression (pp. 1-12). Wiley. https://doi.org/10.1002/9781119057574. whbva104

Association for Behavior Analysis International. (n.d.). Verified course sequence program: Culturo-behavior science. https://www.abainternational.org/ves/culturo-behavioral-science.aspx

Azrin, N. H., \& Lindsley, O. R. (1956). The reinforcement of cooperation between children. Journal of Abnormal and Social Psychology, 52(1), 100-102. https://doi.org/10.1037/h0042490

Francis Bacon. (n.d.). Bartleby.com. https://www.bartleby.com/100/139.39.html

Baum, W. M. (2018). Multiscale behavior analysis and molar behaviorism: An overview. Journal of the Experimental Analysis of Behavior, 110(3), 302-322. https://doi.org/10.1002/jeab.476

Baum, F., MacDougall, C., \& Smith, D. (2006). Participatory action research. Journal of Epidemiology and Community Health, 60(10), 854-857. https://doi.org/10.1136/jech.2004.028662

Behavior Analyst Certification Board. (n.d.). Board Certified Behavior Analyst. https://www.bacb.com/bcba/

Bento, F., \& Couto, K. C. (2021). A behavioral perspective on community resilience during the Covid-19 pandemic: The case of paraisópolis in São Paulo, Brazil. Sustainability, 13(3), 1-18. https://doi.org/10. 3390/su13031447

Bento, F., Tagliabue, M., \& Sandaker, I. (2020). Complex systems and social behavior: Bridging social networks and behavior analysis. In T. M. Cihon \& M. A. Mattaini (Eds.), Behavior science perspectives on culture and community (pp. 67-91). Springer.

Benvenuti, M. F. L., de Toledo, T. F. N., Velasco, S. M., \& Durate, F. M. (2018). Behavior and illusions: A model to study superstition in a participant replacement experiment. Psicologia: Reflexão e Crítica, 31, 19. https://doi.org/10.1186/s41155-018-0097-9

Biglan, A. (1995). Changing cultural practices: A contextualist framework for intervention research. Context Press.

Biglan, A. (2009). Increasing psychological flexibility to influence cultural evolution. Behavior and Social Issues, 18, 1-10. https://doi.org/10.5210/bsi.v18i1.2280

Biglan, A., Elfner, K., Garbacz, S. A., Komro, K., Prinz, R. J., Weist, M. D., Wilson, D. K., \& Zarling, A. (2020). A strategic plan for strengthening America's families: A brief from the Coalition of Behavioral Science Organizations. Clinical Child and Family Psychology Review, 23, 153-175. https://doi.org/10. 1007/s10567-020-00318-0

Borba, A. (2019). The selection of different interlocked behavioral contingencies and maintenance of common pool resources: The case of the production of açaí berries in the Brazilian Amazon. Behavior and Social Issues, 28(1), 229-247. https://doi.org/10.1007/s42822-019-00016-9

Branch, M. N. (2006). Reactions of a laboratory behavioral scientist to a "think tank" on metacontingencies and cultural analysis. Behavior and Social Issues, 15(1), 6-10. https://doi.org/10.5210/bsi.v15i1.343

Brethower, D. M. (1970). The classroom as a self-modifying system [Unpublished doctoral dissertation]. University of Michigan. 
Brethower, D. M. (2008). Historical background for HPT certification standard 2, take a systems view, part 2. Performance Improvement, 47(4), 15-24. https://doi.org/10.1002/pfi.198

Brownson, R. C., Burke, T. A., Colditz, G. A., \& Samet, J. M. (2020). Reimagining public health in the aftermath of a pandemic. American Journal of Public Health, 110, 1605-1610. https://doi.org/10.2105/ AJPH.2020.305861

Caldwell, C. A., \& Millen, A. E. (2008a). Experimental models for testing hypotheses about cumulative cultural evolution. Evolution and Human Behavior, 29, 165-171. https://doi.org/10.1016/j. evolhumbehav.2007.12.001

Caldwell, C. A., \& Millen, A. E. (2008b). Studying cumulative cultural evolution in the laboratory. Philosophical Transactions of the Royal Society, B: Biological Sciences, 363, 3529-3539. https://doi. org/10.1098/rstb.2008.0133

Caldwell, C. A., \& Millen, A. E. (2009). Social learning mechanisms and cumulative cultural evolution: Is imitation necessary? Psychological Science, 20, 1478-1483. https://doi.org/10.1111/j.1467-9280.2009. 02469.x

Carvalho, L. C. D., Sandaker, I., \& Ree, G. (2017). An ethnographic study of tagging cultures. Behavior and Social Issues, 26, 67-94. https://doi.org/10.5210/bsi.v.26i0.6621

Castelfranchi, C. (2007). Six critical remarks on science and the construction of the knowledge society. Journal of Science Communication, 6(4), 1-3. https://doi.org/10.22323/2.06040303

Chance, P. (2007). The ultimate challenge: Prove B. F. Skinner wrong. The Behavior Analyst, 30(2), 153-160. https://doi.org/10.1007/bf03392152

Cihon, T. M., \& Kazaoka, K. (2021). A cultural e (Eds.), Compassion and social justice in applied behaviour analysis: A collection of essays (pp. 100-106). Informa.

Cihon, T. M., \& Mattaini, M. A. (2019). Editorial: Emerging cultural and behavioral systems science. Perspectives on Behavior Science, 42(4), 699-711. https://doi.org/10.1007/s40614-019-00237-8

Cihon, T. M., \& Mattaini, M. A. (Eds.). (2020a). Behavior science perspectives on culture and community. Springer.

Cihon, T. M., \& Mattaini, M. A. (2020b). History and progress in cultural and community science. In T. M. Cihon \& M. A. Mattaini (Eds.), Behavior science perspectives on culture and community (pp. 1-21). Springer.

Cihon, T. M., Becker, A., Ortu, D., \& Glenn, S. S. (2020). Multiple perspectives on establishing a research lab for culturo-behavior science. In T. M. Cihon \& M. A. Mattaini (Eds.), Behavior science perspectives on culture and community (pp. 93-117). Springer.

Cihon, T. M., Borba, A., Lopez, C., Kazaoka, K., \& Carvahlo, L. (2020). Experimental analysis in culturobehavior science: The search for basic processes. In T. M. Cihon \& M. A. Mattaini (Eds.), Behavior science perspectives on culture and community (pp. 119-150). Springer.

Cihon, T. M., Walker, D. J., Kazaoka, K., \& Pritchett, M. (2020). Ethics for cultural behavior science and practice. In T. M. Cihon \& M. A. Mattaini (Eds.), Behavior science perspectives on culture and community (pp. 195-219). Springer.

Cihon, T. M., Borba, A., Smith, M., Kim, A., Pine, S., \& Gutierrez, E. (2021). Teaching high school students to care using behavior science. [Manuscript in preparation]. Department of Behavior Analysis, University of North Texas.

Community Toolbox. (2021). Table of contents. University of Kansas. https://ctb.ku.edu/en/table-of-contents

Couto, K. C., \& Sandaker, I. (2016). Natural, behavioral, and cultural selection-analysis: An integrative approach. Behavior and Social Issues, 43, 27-33. https://doi.org/10.5210/bsi.v.25i0.6891

Cran, S., Cihon, T. M., Borba, A., Kazaoka, K., \& Smith, M. (2021). An in-depth look at community gardens: Practices that support community garden longevity. [Manuscript in preparation]. Department of Behavior Analysis, University of North Texas.

Crawford, S. (1983). The origin and development of a concept: The information society. Bulletin of the Medical Library Association, 71(4), 380-385.

de Toledo, T. F. N., Benvenuti, M. F. L., Sampaio, A. A. S., Marques, N. S., dos Anjos Cabral, P. A., de Souza Araújo, L. A., Machado, L. R., \& Moreira, L. R. (2015). Free culturant: A software for the experimental study of behavioral and cultural selection. Psychology \& Neuroscience, 8(3), 366-384. https://doi.org/10.1037/pne0000016

de Toledo, T. F. N., Benvenuti, M. L., Marques, N., \& Glenn, S. (2020). Schedule performance as a baseline for the experimental analysis of coordinated behavior: Same or different units of analysis? The Psychological Record.

Diener, L., McGee, H., \& Miguel, C. (2009). An integrated approach for conducting a behavioral systems analysis. Journal of Organizational Behavior Management, 29(2), 108-135. https://doi.org/10.1080/ 01608060902874534 
Dixon, M. R., Belisle, J., Rehfeldt, R. A., \& Root, W. B. (2018). Why we are still not acting to save the world: The upward challenge of a post-Skinnerian behavior science. Perspectives on Behavior Science, 41(1), 241-267. https://doi.org/10.1007/s40614-018-0162-9

Dyball, R., \& Newell, B. (Eds.). (2015). Understanding human ecology. Routledge.

Evans, A. L., Bulla, A. J., \& Kieta, A. R. (2021). The precision teaching system: A synthesized definition, concept analysis, and process. Behavior Analysis Practice. Advance online publication. https://doi.org/10. 1007/s40617-020-00502-2

Fritz, M. (1962). The production and distribution of knowledge in the United States. Princeton.

Fryling, M., Rehfeldt, R. A., Tarbox, J., \& Hayes, L. J. (Eds.). (2020). Applied behavior analysis of language and cognition: Core concepts and principles for practitioners. Context Press.

Gelino, B. W., Erath, T. G., Seniuk, H. A., Luke, M. M., Berry, M. S., Fuqua, R. W., \& Reed, D. D. (2020). Global sustainability: A behavior analytic approach. In T. M. Cihon \& M. A. Mattaini (Eds.), Behavior science perspectives on culture and community (pp. 257-281). Springer.

Glenn, S. S. (2004). Individual behavior, culture, and social change. The Behavior Analyst, 27(2), $133-151$. https://doi.org/10.1007/bf03393175

Glenn, S. S., Malott, M. E., Andery Benvenuti, M., Houmanfar, R., Sandaker, I., Todorov, J. C., Tourinho, E. Z., \& Vasconcelos, L. (2016). Toward consistent terminology in a behaviorist approach to cultural analysis. Behavior and Social Issues, 25, 11-27. https://doi.org/10.5210/bsi.v25i0.6634

Grant, L., \& Forrest, M. (2020). Can stories influence sustainable behavior? In T. M. Cihon \& M. A. Mattaini (Eds.), Behavior science perspectives on culture and community (pp. 283-306). Springer.

Herrnstein, R. J. (1970). On the law of effect. Journal of the Experimental Analysis of Behavior, 13(2), 243266. https://doi.org/10.1901/jeab.1970.13-243

Heward, W. L., \& Dunne, J. D. (1993). A teleconference with Professor Fred S. Keller. The Behavior Analyst, 16(2), 341-345. https://doi.org/10.1007/bf03392642

Higgins, S. T., Morris, E. K., \& Johnson, L. M. (1989). Social transmission of superstitious behavior in preschool children. Psychological Record, 39, 307-323. https://doi.org/10.1007/BF03395883

Holland, J. G. (1978). Behaviorism: Part of the problem or part of the solution? Journal of Applied Behavior Analysis, 11(1), 163-174. https://doi.org/10.1901/jaba.1978.11-163

Houmanfar, R. A., Rodrigues, N. J., \& Ward, T. A. (2010). Emergence \& metacontingency: Points of contact and departure. Behavior and Social Issues, 19, 78-103. https://doi.org/10.5210/bsi.v19i0.3065

Hunter, C. S. (2012). Analyzing behavioral and cultural selection contingencies. Revista Latinoamericana de Psicologia, 44(1), 43-54.

Innerarity, D. (2012). Power and knowledge: The politics of the knowledge society. European Journal of Social Theory, 16(1), 3-16. https://doi.org/10.1177/1368431012468801

Jacob, S. (2012). Health care in 2020: Where uncertain reform, bad habits, too few doctors, and skyrocketing costs are taking us. Dorsam Publishing.

Keller, F. (1968). Good-bye teacher. Journal of Applied Behavior Analysis, 1, 79-89. https://doi.org/10.1901/ jaba.1968.1-79

Khasnabis, C., Heinicke, M. K., Achu, K., Jubah, K. A., Brodtkorb, S., Chervin, P., Coleridge, P., Davies, M., Deepak, S., Eklindh, K., Goerdt, A., Greer, C., Heinicke-Motsch, K., Hooper, D., Ilagan, V. B., Jessup, J., Khasnabis, C., Mulligan, D., Murray, B....Wabuge-Mwangi, R. (Eds.). (2010). Community-based rehabilitation: CBR guidelines. World Health Organization. https:/www.ncbi.nlm.nih.gov/books/ NBK310940/

Krispin, J. V. (2017). Positive feedback loops of metacontingencies: A new conceptualization of cultural-level selection. Behavior and Social Issues, 26, 95-110. https://doi.org/10.5210/bsi.v.26i0.7397

Krispin, J. (2019). Culturo-behavioral hypercycles and the metacontingency: Incorporating self-organizing dynamics into an expanded model of cultural change. Perspectives on Behavior Science, 42(4), 869-887. https://doi.org/10.1007/s40614-019-00212-3

Lamal, P. A. (Ed.). (1991). Behavioral analysis of societies and cultural practices. Hemisphere Publishing.

Lamal, P. A. (Ed.). (1997). Cultural contingencies: Behavior analytic perspectives on cultural practices. Praeger.

Ledoux, S. F. (2014). Running out of time-Introducing behaviorology to help solve global problems. BehaveTech Publishing.

Ledoux, S. F. (2017). What causes human behavior-Stars, selves, or contingencies? BehaveTech Publishing.

Leigland, S. (2011). Beyond freedom and dignity at 40: Comments on behavioral science, the future, and Chance (2007). The Behavior Analyst, 34(2), 283-295. https://doi.org/10.1007/bf03392258

Levin, K., Cashore, B., Bernstein, S., \& Auld, G. (2012). Overcoming the tragedy of super wicked problems: Constraining our future selves to ameliorate global climate change. Policy Sciences, 45, 123-152. https:// doi.org/10.1007/s1 1077-012-9151-0 
Lewin, K. (1943). Defining the "field at a given time". Psychological Review, 50(3), 292-310. https://doi.org/ 10.1037/h0062738

Lopez, C., Cihon, T. M., Borba, A., \& Becker, A. (In press). An exploration of cooperation during an asymmetric iterated prisoner's dilemma game. Behavior and Social Issues.

Ludwig, T. D., \& Houmanfar, R. (Eds.). (2010). Understanding complexity in organizations: Behavioral systems. Routledge.

Mace, F. C., \& Critchfield, T. S. (2010). Translational research in behavior analysis: Historical traditions and imperative for the future. Journal of Experimental Analysis of Behavior, 93(3), 293-312. https://doi.org/ 10.1901/jeab.2010.93-293

Malott, M. E. (2003). Paradox of organizational change: Engineering organizations with behavioral systems analysis. Context Press.

Malott, M. E. (2016). Selection of business practices in the midst of evolving complexity. Journal of Organizational Behavior Management, 36(2-3), 103-122. https://doi.org/10.1080/01608061.2016. 1200511

Malott, M. E., \& Glenn, S. S. (2006). Targets of intervention in cultural and behavioral change. Behavior and Social Issues, 15, 31-56. https://doi.org/10.5210/bsi.v15i1.344

Malott, M. E., \& Glenn, S. S. (2019). Integrating institutional and culturo-behavioral analyses in the management of common pool resources: Application to an inland lake in Michigan. Behavior and Social Issues, 28(1), 248-268. https://doi.org/10.1007/s42822-019-00014-x

Marr, M. J. (2006). Behavior analysis and social dynamics: Some questions and concerns. Behavior and Social Issues, 15(1), 57-67. https://doi.org/10.5210/bsi.v15i1.345

Mattaini, M. A. (2006). Will cultural analysis become a science? Behavior and Social Issues, 15(1), 68-80. https://doi.org/10.5210/bsi.v15i1.380

Mattaini, M. A. (2013). Strategic nonviolent power: The science of satyagraha. Athabasca University Press.

Mattaini, M. A. (2019). Out of the lab: Shaping an ecological and constructional cultural systems science. Perspectives on Behavior Science, 42(4), 713-731. https://doi.org/10.1007/s40614-019-00208-Z

Mattaini, M. A. (2020). Cultural systems analysis: An emerging science. In T. M. Cihon \& M. A. Mattaini (Eds.), Behavior science perspectives on culture and community (pp. 43-65). Springer.

Mattaini, M. A., \& Cihon, T. M. (2019). Editorial: A new beginning and a new commitment. Behavior and Social Issues, 28, 1-7. https://doi.org/10.1007/s42822-019-00023-w

Mattaini, M. A., \& Luke, M. (2014). Editorial: "Saving the world" with a matrix. Behavior and Social Issues, 23, 1-4. https://doi.org/10.5210/bsi.v23i0.5860

Mattaini, M. A., \& Rehfeldt, R. A. (2020). Rendezvous with truth and discovery. Behavior and Social Issues. Advance online publication. https://doi.org/10.1007/s42822-020-00034-y

Mattaini, M. A., Esquierdo-Leal, J., Ardila Sánchez, J. G., Richling, S. M., \& Ethridge, A. N. (2020). Public policy advocacy in culturo-behavior science. In T. M. Cihon \& M. A. Mattaini (Eds.), Behavior science perspectives on culture and community (pp. 384 412). Springer.

Mayer, G. R. (1995). Preventing antisocial behavior in the schools. Journal of Applied Behavior Analysis, 28, 467-478 https://www.ncbi.nlm.nih.gov/pmc/articles/PMC1279853/pdf/jaba00006-0082.pdf

Mobus, G. E., \& Kalton, M. C. (2015). Principles of systems science. Springer.

Morford, Z. H., \& Cihon, T. M. (2013). Developing an experimental analysis of metacontingencies: Considerations regarding cooperation in a four-person prisoner's dilemma game. Behavior and Social Issues, 22, 5-20. https://doi.org/10.5210/bsi.v22i0.4207

Morris, E. K., \& Midgley, B. N. (1990). Some historical and conceptual foundations of ecobehavioral analysis. In S. R. Schroeder (Ed.), Ecobehavioral analysis and developmental disabilities: Disorders of human learning, behavior, and communication (pp. 1-32). Springer.

Neef, N. A., \& Peterson, S. M. (2003). Developmental disabilities: Scientific inquiry and interactions in behavior analysis. In K. Lattal \& P. N. Chase (Eds.), Behavior theory and philosophy (pp. 369-389). Springer.

Ortu, D., Becker, A. M., Woelz, T. A. R., \& Glenn, S. S. (2012). An iterated four-player prisoner's dilemma game with an external selecting agent: A metacontingency experiment. Revista Latinoamericana de Psicología, 44(1), 111-120.

Ramos, C. C., Costa, T. D., Borba, A., \& da Silva Barros, R. (2016). Uma abordagem comportamental para a descrição de competências em uma instituição pública federal [A behavioral approach to description of competences in a federal public institution]. Perspectivas Em Análise Do Comportamento, 7(1), 133-146. https://doi.org/10.18761/pac.2015.029

Rittel, H. W. J., \& Webber, M. M. (1973). Dilemmas in a general theory of planning. Policy Sciences, 4(2), 155-169. https://doi.org/10.1007/BF01405730 
Roose, K. M., \& Mattaini, M. A. (2020). Challenging violence: Toward a 21st century, science-based "constructive program". In T. M. Cihon \& M. A. Mattaini (Eds.), Behavior science perspectives on culture and community (pp. 307-331). Springer.

Rumph, R., Ninness, C., McCuller, G., \& Ninness, S. K. (2005). Guest editorial: Twenty years later, commentary on Skinner's "Why we are not acting to save the world". Behavior and Social Issues, 14(1), 1-6. https://doi.org/10.5210/bsi.v14i1.117

Sangaramoorthy, T., \& Kroeger, K. A. (2020). Rapid ethnographic assessments: A practical approach and toolkit for collaborative community research. Routledge.

Schmitt, D. R. (1998). Social behavior. In K. A. Lattal \& M. Perone (Eds.), Handbook of research methods in human operant behavior (pp. 471-505). Plenum Press. https://doi.org/10.1007/978-1-4899-1947-2_15

Schroeder, S. R. (Ed.). (1990). Ecobehavioral analysis and developmental disabilities: The twenty-first century. Springer-Verlag.

Seniuk, H. A., Cihon, T. M., Benson, M., \& Luke, M. (2019). Making a footprint in environmental sustainability: A behavioral systems approach to engaging behavior analysts. Perspectives on Behavior Science, 42(4), 911-926. https://doi.org/10.1007/s40614-019-00233-y

Sidman, M. (1994). Equivalence relations and behavior: A research story. Authors Cooperative.

Sidman, M. (2011). Can an understanding of basic research facilitate the effectiveness of practitioners? Reflections and personal perspectives. Journal of Applied Behavior Analysis, 44(4), 973-991. https:// doi.org/10.1901/jaba.2011.44-973

Skinner, B. F. (1948a). Walden two. Prentice Hall.

Skinner, B. F. (1948b). 'Superstition' in the pigeon. Journal of Experimental Psychology, 38(2), 168-172. https://doi.org/10.1037/h0055873

Skinner, B. F. (1953). Science and human behavior. Macmillan.

Skinner, B. F. (1957). Verbal behavior. Copley Publishing Group.

Skinner, B. F. (1968). The technology of teaching. B. F.

Skinner, B. F. (1974). About behaviorism. Knopf.

Skinner, B. F. (1981). Selection by consequences. Science, 213, 501-504. https://doi.org/10.1126/science. 7244649

Substance Abuse and Mental Health Services Administration. (2019). A Guide to SAMHSA's strategic prevention framework. Center for Substance Abuse Prevention.

Todorov, J. C. (2009). Behavioral analysis of non-experimental data associated with cultural practices. Behavior and Social Issues, 1, 10-14. https://doi.org/10.5210/bsi.v18i1.2756

Todorov, J. C., \& Lemos, R. F. (2020). Applying behavioral science to large-scale social change. In T. M. Cihon \& M. A. Mattaini (Eds.), Behavior science perspectives on culture and community (pp. 171-193). Springer.

Todorov, J. C., \& Malott, M. E. (2005). Think tank on metacontingencies and cultural analysis. The ABA Newsletter, 28(3), 11.

U.S. Department of Health and Human Services. (n.d.). Healthy people. https://health.gov/healthypeople

United Nations Educational, Scientific and Cultural Organization. (2005). Toward knowledge societies. UNESCO World Report. Imprimerie Corlet. https://doi.org/10.18356/9789210059077

University of North Texas College of Health and Public Service. (n.d.). Behavior analysis research. https:// hps.unt.edu/behv/behavior-analysis-research

Vichi, C., Andery, M. A. P. A., \& Glenn, S. S. (2009). A metacontingency experiment: The effects of contingent consequences on patterns of interlocking contingencies of reinforcement. Behavior and Social Issues, 18, 41-57. https://doi.org/10.5210/bsi.v18i1.2292

von Bertalanffy, L. (1968). General system theory. George Braziller.

Watson-Thompson, J., Francisco, V. T., \& Anderson-Carpenter, K. D. (2020). A behavioral community approach to community health and development: Tools for collaborative action. In T. M. Cihon \& M. A. Mattaini (Eds.), Behavior science perspectives on culture and community (pp. 333-356). Springer.

Watson-Thompson, J., Jessop, N., Hassaballa, I., Vanchy, P., Henderson, J., \& Moore, C. (2020). Together Helping Reduce Youth Violence for Equity (ThYve): Examining the development of a comprehensive multisectoral approach to youth violence prevention. American Journal of Community Psychology, 66(34), 244-255. https://doi.org/10.1002/ajcp.12449

Zilio, D. (2019). On the function of science: An overview of 30 years of publications on metacontingency. Behavior and Social Issues, 28, 46-76. https://doi.org/10.1007/s42822-019-00006-x 